Article

\title{
Epigenetic Inactivation of the Tumor Suppressor IRX1 Occurs Frequently in Lung Adenocarcinoma and Its Silencing Is Associated with Impaired Prognosis
}

\author{
Miriam M. Küster ${ }^{1}$, Marc A. Schneider ${ }^{2,3}{ }^{\circledR}$, Antje M. Richter ${ }^{1}{ }^{\circledR}$, Sarah Richtmann ${ }^{2,3}{ }^{3}$, \\ Hauke Winter $^{3,4}$, Mark Kriegsmann ${ }^{3,5}\left(\mathbb{D}\right.$, Soni S. Pullamsetti ${ }^{3,6}\left(\mathbb{D}\right.$, Thorsten Stiewe ${ }^{3,7}(\mathbb{D}$, \\ Rajkumar Savai ${ }^{3,6}\left(\mathbb{D}\right.$, Thomas Muley ${ }^{2,3}$ and Reinhard H. Dammann 1,3,* \\ 1 Faculty of Biology, Institute for Genetics, Justus-Liebig-University Giessen, 35392 Giessen, Germany; \\ Miriam.Kuester@gen.bio.uni-giessen.de (M.M.K.); antje.m.richter@gen.bio.uni-giessen.de (A.M.R.) \\ 2 Translational Research Unit, Thoraxklinik at Heidelberg University Hospital, 69126 Heidelberg, Germany; \\ Marc.Schneider@med.uni-heidelberg.de (M.A.S.); Sarah.Richtmann@med.uni-heidelberg.de (S.R.); \\ Thomas.Muley@med.uni-heidelberg.de (T.M.) \\ 3 Marburg Lung Center (UGMLC) and Translational Lung Research Center (TLRC) Heidelberg, \\ German Center for Lung Research (DZL), Universities of Giessen, 35392 Giessen, Germany; \\ Hauke.Winter@med.uni-heidelberg.de (H.W.); mark.kriegsmann@med.uni-heidelberg.de (M.K.); \\ soni.pullamsetti@mpi-bn.mpg.de (S.S.P.); thorsten.stiewe@staff.uni-marburg.de (T.S.); \\ Rajkumar.Savai@mpi-bn.mpg.de (R.S.) \\ 4 Department of Surgery, Thoraxklinik at Heidelberg University Hospital, 69126 Heidelberg, Germany \\ 5 Department of Pathology, Institute of Pathology, University Hospital Heidelberg, \\ 69120 Heidelberg, Germany \\ 6 Department of Lung Development and Remodeling, Max-Planck-Institute for Heart and Lung Research, \\ 61231 Bad Nauheim, Germany \\ 7 Institute of Molecular Oncology, Member of the German Center for Lung Research (DZL), \\ Philipps-University, 35032 Marburg, Germany \\ * Correspondence: reinhard.dammann@gen.bio.uni-giessen.de; Tel.: +41-641-993-5462
}

Received: 16 October 2020; Accepted: 24 November 2020; Published: 26 November 2020

Simple Summary: Lung cancer is one of the most commonly diagnosed cancers worldwide and the most common cause of cancer-related deaths. During lung carcinogenesis, epigenetic alteration of tumor-related genes is a frequent event and especially silencing of tumor suppressor genes is often found. In our work, we identified Iroquois homeobox 1 (IRX1) from the lung cancer susceptibility locus $5 \mathrm{p} 15.33$, as an epigenetically silenced target gene. We report frequent epigenetic inactivation of IRX1 in primary lung adenocarcinoma. Moreover, reduced expression and hypermethylation of IRX1 was correlated with an impaired prognosis of patients with lung adenocarcinoma. Functionally, IRX1 overexpression induced signs of apoptosis including fragmented nuclei and expression of a proapoptotic regulator. Loss of IRX1 expression by its promoter hypermethylation can serve as a diagnostic and prognostic lung cancer biomarker.

\begin{abstract}
Iroquois homeobox (IRX) encodes members of homeodomain containing genes which are involved in development and differentiation. Since it has been reported that the IRX1 gene is localized in a lung cancer susceptibility locus, the epigenetic regulation and function of IRX1 was investigated in lung carcinogenesis. We observed frequent hypermethylation of the IRX1 promoter in non-small cell lung cancer (NSCLC) compared to small cell lung cancer (SCLC). Aberrant IRX1 methylation was significantly correlated with reduced IRX1 expression. In normal lung samples, the IRX1 promoter showed lower median DNA methylation levels $(<10 \%)$ compared to primary adenocarcinoma (ADC, 22\%) and squamous cell carcinoma (SQCC, 14\%). A significant hypermethylation and downregulation of IRX1 was detected in ADC and SQCC compared to matching normal lung samples $(p<0.0001)$. Low IRX1 expression was significantly correlated with
\end{abstract}


impaired prognosis of ADC patients $(p=0.001)$. Reduced survival probability was also associated with higher IRX1 promoter methylation $(p=0.02)$. Inhibition of DNA methyltransferase (DNMT) activity reactivated IRX1 expression in human lung cancer cell lines. Induced DNMT3A and EZH2 expression was correlated with downregulation of IRX1. On the cellular level, IRX1 exhibits nuclear localization and expression of IRX1 induced fragmented nuclei in cancer cells. Localization of IRX1 and induction of aberrant nuclei were dependent on the presence of the homeobox of IRX1. By data mining, we showed that IRX1 is negatively correlated with oncogenic pathways and IRX1 expression induces the proapoptotic regulator $B A X$. In conclusion, we report that $I R X 1$ expression is significantly associated with improved survival probability of ADC patients. IRX1 hypermethylation may serve as molecular biomarker for ADC diagnosis and prognosis. Our data suggest that IRX1 acts as an epigenetically regulated tumor suppressor in the pathogenesis of lung cancer.

Keywords: IRX; DNA methylation; epigenetic; lung cancer; adenocarcinoma; apoptosis; tumor suppressor; homeobox

\section{Introduction}

Lung cancer is one of the most commonly diagnosed cancers worldwide (1.82 million in 2012) and the most common cause of cancer-related deaths (1.6 million in 2012) [1]. Lung cancer is classified into small cell lung cancer (SCLC) and non-small cell lung cancer (NSCLC) which is further subdivided into different entities including adenocarcinoma (ADC), squamous cell carcinoma (SQCC), and large cell carcinoma (LC). Whereas SCLC originates from neuroendocrine cells of the lung, ADC and SQCC arises from epithelial cells that undergo distinct genetic and epigenetic changes. During lung carcinogenesis, epigenetic alteration of tumor-related genes is a frequent event and especially silencing of tumor suppressor genes is often found [2]. The hallmark of the epigenetic inactivation is the hypermethylation of $\mathrm{CpG}$ island promoters through 5-methyl-cytosine that leads to chromatin silencing of the corresponding gene [3]. In our previous work, we identified several tumor suppressor genes (e.g., RASSF1A, RASSF10, ABCB4, DUSP2, and ZAR1) that are epigenetically silenced by DNA hypermethylation in human carcinogenesis including lung tumors [4].

Homeobox containing genes have been shown to play a central role in embryonic development, in cellular differentiation, and in pathogenesis of cancer [5,6]. In drosophila, the Iroquois gene (IRO) encodes a prepattern gene that controls the formation of bristles on the thorax [7]. In human, the Iroquois homeobox (IRX) family consists of six members (IRX1-IRX6) that contain a homeobox and a so called IRO box [8]. The IRX gene are transcription factors that play key roles in differentiation and development $[9,10]$. These six IRX genes are organized into two clusters of three, each are located on cytoband 5p15.33 (IRX1, IRX2, and IRX4) and on cytoband 16q12.2 (IRX3, IRX5, and IRX6) [5,8].

The IRX1 gene encodes a polypeptide of 480 amino acids (aa) and the protein contains a homeobox at position 145-184, a HB1, ASXL, restriction endonuclease helix-turn-helix (HARE-HTH) domain (position 188-247) and the IRO box at position 313-326 (Figure 1a). As mentioned above, IRX1 is located on cytoband 5 p15.33 and the loss of this chromosomal region (LOH; loss of heterozygosity) has been reported in different tumor types including gastric cancer [11], cervix carcinoma [12], colorectal cancer [13], and lung cancer [14]. The promoter region of IRX1 is located in a CpG island (Figure 1b) and hypermethylation of $I R X 1$ has been found in gastric cancer [15], head and neck squamous carcinoma [16], and other cancer entities [17-19]. Functional data indicate that IRX1 acts as an epigenetically regulated tumor suppressor in different types of cancer $[15,20]$.

The chromosomal region 5p15.33, that harbors the IRX1 gene, has been reported as a susceptibility locus for lung cancer [21-24]. However, causal genetic and epigenetic variants in this cytoband have not been fully uncovered. In our study, we investigated the epigenetic regulation and the tumor suppressor function of IRX1 in the pathogenesis of lung cancer. Here, we report frequent epigenetic inactivation of 
IRX1 in primary lung adenocarcinoma (ADC). Moreover, reduced expression and hypermethylation of IRX1 was correlated with an impaired prognosis of ADC patients. Gene set enrichment analysis showed a negative correlation of IRX1 expression with oncogenic hallmarks. Functionally, IRX1 overexpression induced signs of apoptosis including fragmented nuclei and expression of the proapoptotic regulator $B A X$.

\section{Results}

\subsection{Epigenetic Silencing of IRX1 in Cancer Cells}

It has been reported that the chromosomal region $5 \mathrm{p} 15.33$ harbors a lung cancer susceptibility locus [21-24] and we analyzed the epigenetic regulation of $I R X 1$ that is located in this specific cytoband (Figure 1). Expression of IRX1 is detected in lung tissue, but also other normal samples including skin, kidney cortex, salivary gland, and breast tissue (Figure S1a) [25]. The IRX1 gene is localized in an $8.6 \mathrm{~kb}$ CpG island containing the whole gene including $1.7 \mathrm{~kb}$ upstream of its transcriptional start site (TSS, Figure 1b). We analyzed the promoter methylation of the IRX1 promoter region of five NSCLC cell lines (A549, A427, HCC15, H322, and H358) and 11 SCLC cell lines (HTB171, HTB175, SCLC21H, SCLC22H, SCLC24H, H82, HTB187, H209, H510, H1092, and H1184) by combined bisulfite restriction analysis (Figure 1c,d). Methylation was determined by a $165 \mathrm{bp}$ TaqI restriction fragment in the proximal IRX1 promoter. We observed partial and full methylation of the diagnostic CpG site for all five NSCLC cell lines, but only for three (HTB171, HTB175, and HTB187) out of 11 SCLC cell lines (Figure 1d). We also found IRX1 promoter hypermethylation in HeLa cells (Figure 1d).

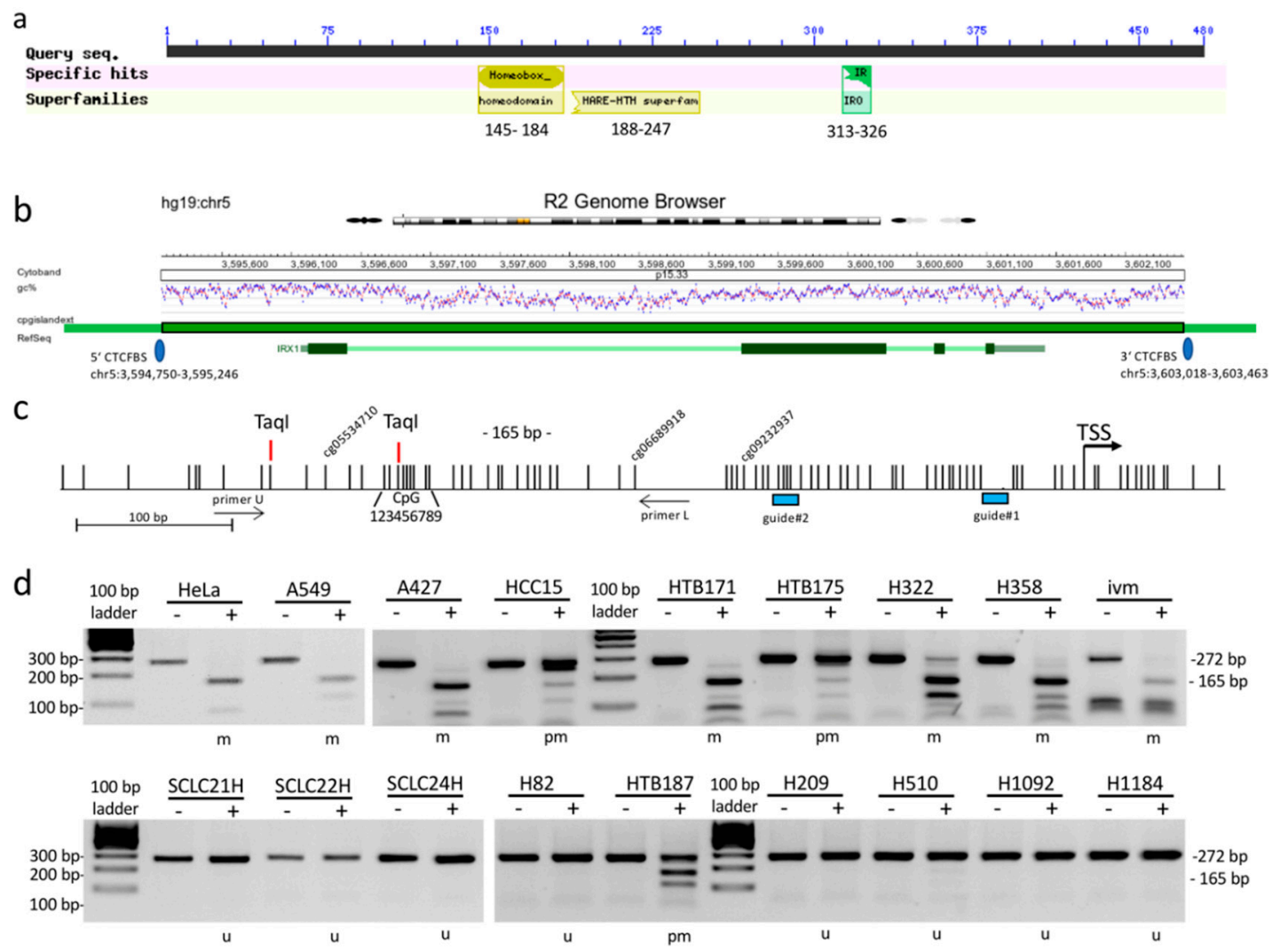

Figure 1. Structure of IRX1 and its methylation analysis in lung cancer. (a) The IRX1 gene encodes a polypeptide of 480 aa and the protein contains a homeobox at position 145-184, a HARE-HTH (HB1, ASXL, restriction endonuclease helix-turn-helix) domain at position 188-247 and the Iroquois (IRO) box at position 313-326 (NCBI tool for conserved domain search) [26] (b) IRX1 is located on chromosome 5 p15.33 in an $8.6 \mathrm{~kb}$ CpG island (dark green box) flanked by the two indicated CTCF binding sites ( $5^{\prime}$ - 
and $3^{\prime}$-CTCFBS) [27]. (c) Overview of the analyzed $675 \mathrm{bp}$ sequence located in the proximal IRX1 promoter region. The transcriptional start site (TSS; arrow) and individual CpG sites (black lines) are depicted by Python vs. CoBRA [28]. For methylation analysis, two TaqI sites of CoBRA, nine CpGs sites $(1,2,3,4,5,6,7,8$, and 9) of bisulfite pyrosequencing, and three CpG sites (cg05534710, cg06689918, and cg09232937) of 450K array are marked. Positions of guide\#1 and guide\#2 for promoter deletion are marked as blue boxes upstream of the IRX1 TSS. (d) A $272 \mathrm{bp}$ fragment of the IRX1 promoter was analyzed by CoBRA in five NSCLC (A549, A427, HCC15, H322, and H358), 11 SCLC (HTB171, HTB175, SCLC21H, SCLC22H, SCLC24H, H82, HTB187, H209, H510, H1092, and H1184), HeLa and in vitro methylated DNA (ivm). PCR products were mock (-) or TaqI (+) digested and analyzed on $2 \%$ agarose gels together with a $100 \mathrm{bp}$ ladder. Unmethylated $(\mathrm{u})$, partially methylated $(\mathrm{pm})$, and methylated $(\mathrm{m})$ samples are indicated.

Downregulation of $I R X 1$ expression was frequently observed in several cancer cell lines compared to leukemia (Figure S1b) and was also found in NSCLC cell lines [29]. Thus, we analyzed the methylation of three 450K array probes (cg05534710, cg06689918, and cg09232937) in 244 normal lung samples and 1028 cancer cell lines (Figure 2a). A significant IRX1 hypermethylation was observed for all three CpG sites in cancer cells (Figure 2a). For cg09232937, the median methylation level was higher in both normal lung (30\% methylation) and cancer cell lines (90\% methylation) compared to the other two CpG sites (normal 10\% and cancer cell lines 20-30\% median methylation), respectively. Next, we correlated the IRX1 hypermethylation at these three CpG sites (cg05534710, cg06689918, and cg09232937) with IRX1 downregulation in these cancer cell lines (Figure 2b). Increased IRX1 methylation was linked with reduced IRX1 expression for all three analyzed CpG sites. Cancer cell lines with low IRX1 methylation ( $<10 \%$ ) exhibited the highest level of IRX1 mRNA levels (Figure 2b). Methylation level at cg09232937 correlated the most significant with the expression of IRX1.
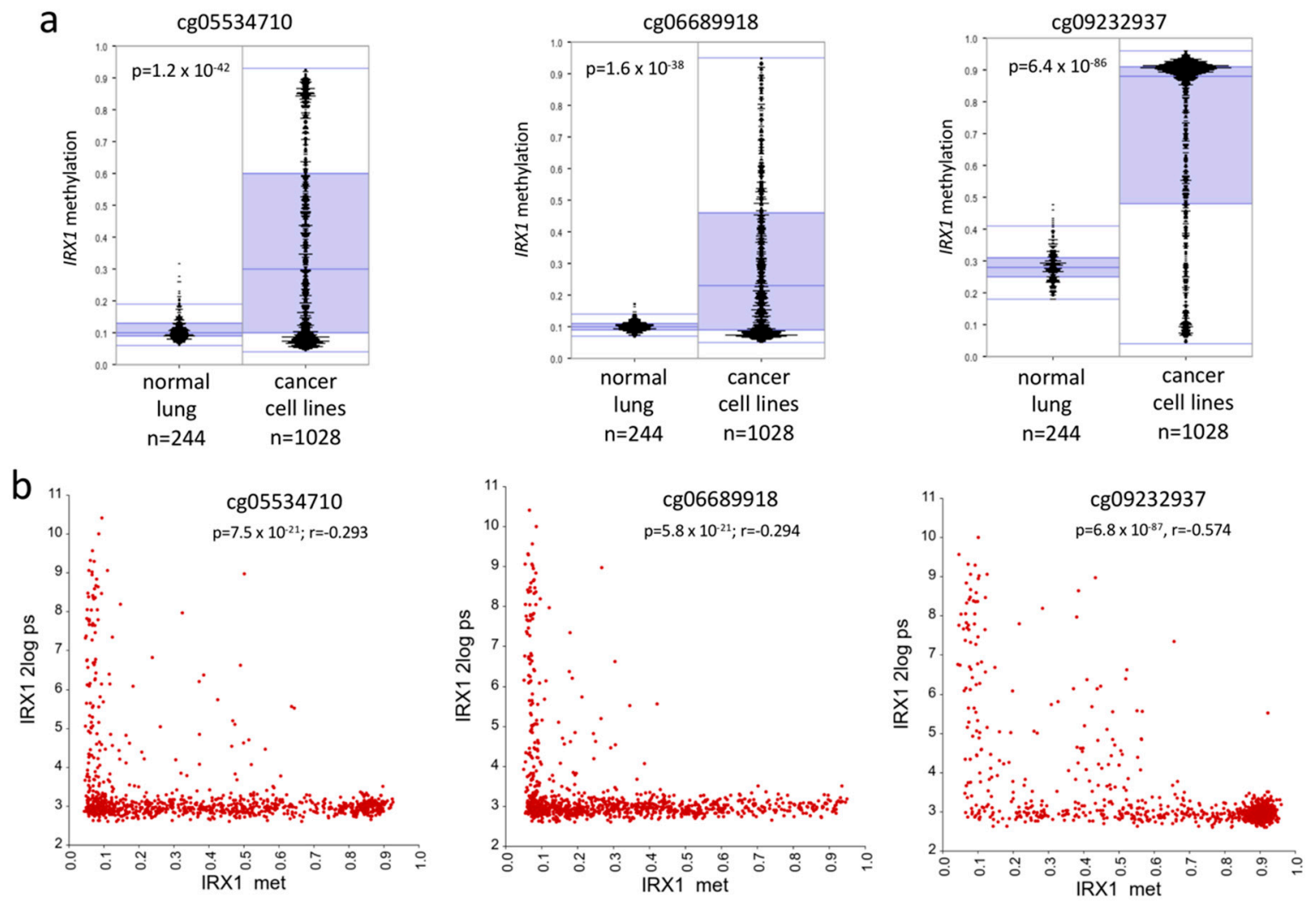

Figure 2. Methylation and expression of IRX1 in cancer cell lines. (a) Methylation level of the IRX1 promoter at the three CpG sites (cg05534710, cg06689918, and cg09232937) were analyzed by Infinium 
Human Methylation 450 BeadChip (ilmnhm450K array) through the R2 Genomics Analysis and Visualization Platform [30]. Methylation of 244 normal lung samples (GSE52401) were compared to methylation of 1028 cancer cell lines (GSE68379). IRX1 methylation levels are plotted in beta-value ( $1=100 \%$ methylation) and $p$-value was calculated by one-way ANOVA. (b) Correlation analysis of IRX1 promoter methylation (beta-value) and IRX1 expression (2log ps). Methylation level of the three CpG sites of cancer cell lines (GSE68379) was plotted for IRX1 expression (11725275_at) in the corresponding mRNA 1017 of cancer cell lines [31]. Significance of correlation was calculated by the R2 platform. $p<0.05$ was considered significant.

\subsection{Epigenetic Inactivation of IRX1 in Lung Adenocarcinoma Is Correlated with Impaired Prognosis}

Subsequently, we analyzed the epigenetic inactivation of IRX1 in 100 lung adenocarcinoma (ADC) and 100 squamous cell carcinoma (SQCC) and the corresponding control samples by bisulfite pyrosequencing and quantitative RT-PCR (Figure 3). Clinicopathological data of all 200 patients with NSCLC are listed in Table S1. Average IRX1 methylation was determined at nine CpG sites (CpG1-9) flanking the TaqI site (CpG3) by sequencing (Figures 1c and 3a). Median methylation levels for all patients are plotted in Figure 3a. In ADC, a higher methylation level (median 22\%) was revealed compared to SQCC (median 14\%). DNA methylation level of a single CpG site showed a similar pattern for all nine CpG sites in both ADC and SQCC (Figure S2). We also analyzed 41 primary small cell lung cancer (SCLC) samples, that were available from our previous study [4]. In SCLC, a low median IRX1 methylation (6\%) was detected (Figure 3a). However, seven SCLC samples exhibited increased methylation levels (50-90\%).
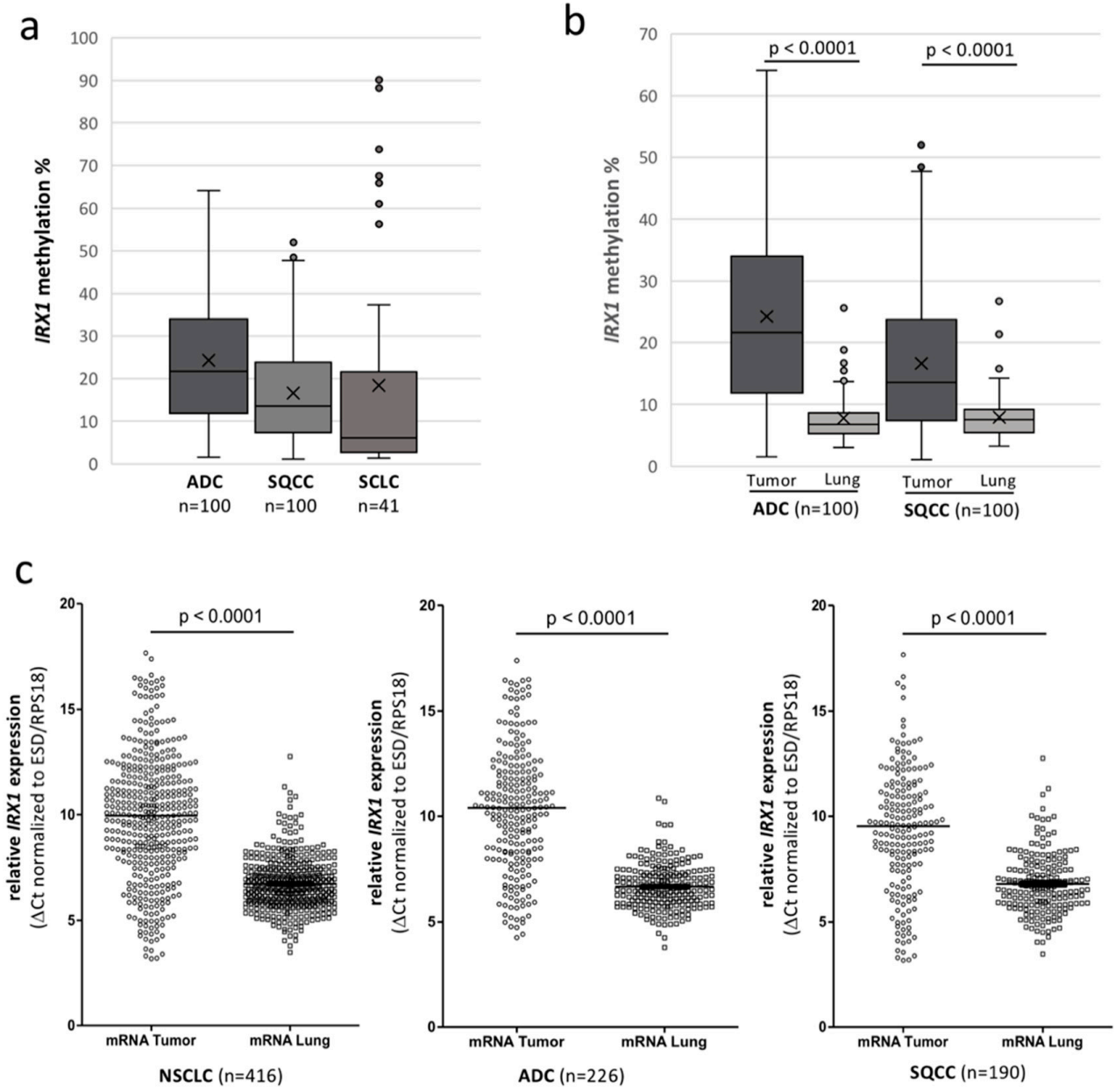

Figure 3. Epigenetic inactivation of $I R X 1$ in primary lung cancers compared to matching lung. (a) Methylation level of the IRX1 promoter at the nine CpG sites was analyzed in 100 adenocarcinoma (ADC), 
100 squamous cell carcinoma (SQCC), and 41 small cell lung cancer (SCLC) samples by bisulfite pyrosequencing. Average CpG methylation levels are depicted by box plot. (b) IRX1 methylation of tumors and corresponding matching lung samples were revealed by pyrosequencing. Average methylation was compared to tumor tissue by box plot and $p$-value was calculated. (c) Relative IRX1 expression in primary tumors and corresponding lung samples. mRNA levels were analyzed by qRTPCR normalized to the housekeeping genes ESD and RPS18 $(\Delta \mathrm{Ct})$. Note that a higher $\triangle \mathrm{Ct}$ value indicates lower IRX1 expression. Median expression levels of IRX1 of NSCLC, ADC, and SQCC and corresponding lung samples are shown and significances ( $p$-values) were calculated. $p<0.05$ was considered significant.

Next, we analyzed the methylation of the nine CpG sites in the corresponding lung tissue of 200 patients with NSCLC and compared the average methylation of ADC and SQCC (Figure 3b and Figure S2). In the matching lung tissue, IRX1 promoter methylation was found at low levels (median $7 \%$ and $8 \%$, respectively) and a significant hypermethylation was found in the corresponding ADC and SQCC ( $p<0.0001)$. To analyze the methylation level of IRX1 in cancer-unrelated tissues, we utilized samples from idiopathic pulmonary artery hypertension (IPAH) patients (Figure S2). Average IRX1 promoter methylation was at about 5\% threshold level, which was lower than the methylation level of normal lung analyzed by $450 \mathrm{~K}$ bead chip (median of $10 \%$ at cg05534710, Figure $2 \mathrm{a}$ ).

Further, we utilized two independent $450 \mathrm{~K}$ bead chip data sets of primary ADC (LUAD) and SQCC (LUSQ) samples to verify the epigenetic inactivation of IRX1 in primary NSCLC by the TCGA Wanderer platform [32]. For ADC, we correlated mean methylation of 463 tumors and 32 normal samples at cg05534710, cg06689918, and cg09232937 and IRX1 expression (Figure S3a). In ADC tumor samples, a significant hypermethylation of all three $\mathrm{CpG}$ sites was found compared to the normal tissues $(p<0.001)$. This increased methylation was inversely correlated with IRX1 expression for these sites (Figure S3a). For SQCC, methylation and expression data were available for 361 tumor samples and 43 normal lung tissues (Figure S3b). A significant increased mean methylation of SQCC was revealed for all three CPG sites compared to normal samples $(p<0.001)$. Hypermethylation was correlated with a reduced expression for all three CpGs of the IRX1 promoter (Figure S3b). Thus, we also analyzed the expression of IRX1 in the available NSCLC RNA samples by qRTPCR (Figure 3c). RNA levels were normalized and reduction of IRX1 expression is shown as $\Delta C$ t values compared to ESD/RPS18 levels (housekeeping genes). In NSCLC, we found a significant reduction of IRX1 expression compared to the matching lung tissues $(p<0.0001)$. This significant reduction was also revealed for ADC and SQCC (Figure 3c). However, in ADC, the reduction of median IRX1 expression was more pronounced than in SQCC. In the corresponding lung disease tissues, this difference was not observed (Figure S3c).

In order to correlate IRX1 expression with patient survival probabilities, we performed the Kaplan-Meier estimator and plotted the data in Figure 4 for all patients with NSCLC, but also for ADC and SQCC patients separately (Figure 4a and Figure S4a). Higher IRX1 expression was associated with a better survival rate of patients with NSCLC $(p=0.001 ; n=226)$, and this was significantly correlated in ADC $(p=0.001 ; n=226)$, but not with SQCC $(p=0.9 ; n=190$; Figure S4a). By data mining, we confirmed this impaired prognosis for lower IRX1 expression in two independent data analyses for lung ADC patients (Figure S4b,c), but not for SQCC patients (Figure S4d) [30,33]. Moreover, an association of low IRX1 expression with advanced NSCLC stages was revealed (Figure S4e).

Next, we correlated IRX1 methylation levels with survival probabilities of patients with NSCLC (Figure $4 b$ ). We observed a significant better survival prognosis for patients with NSCLC harboring a lower CpG8 methylation ( $p=0.015)$. A significant correlation was also found for other CpG sites of IRX1 (Figure S5a). Moreover, lower CpG methylation was also significantly associated with better prognosis for ADC patients ( $p=0.02$; Figure $4 \mathrm{~b}$ ). We also revealed that increased CpG methylation is significantly associated with reduced IRX1 expression ( $p<0.001$; Figure $4 c)$. Additionally, methylation of cg05534710, cg06689918, and cg09232937 was analyzed by the Kaplan-Meier estimator in 461 patients by the MethSurv tool [34] (Figure S5b). We observed that lower IRX1 methylation at the CpG sites 
is correlated with a better prognosis and this trend was significant for $\operatorname{cg} 06689918$ and $\operatorname{cg} 09232937$ ( $p=0.03$ and 0.02 , respectively) (Figure S5a,b).
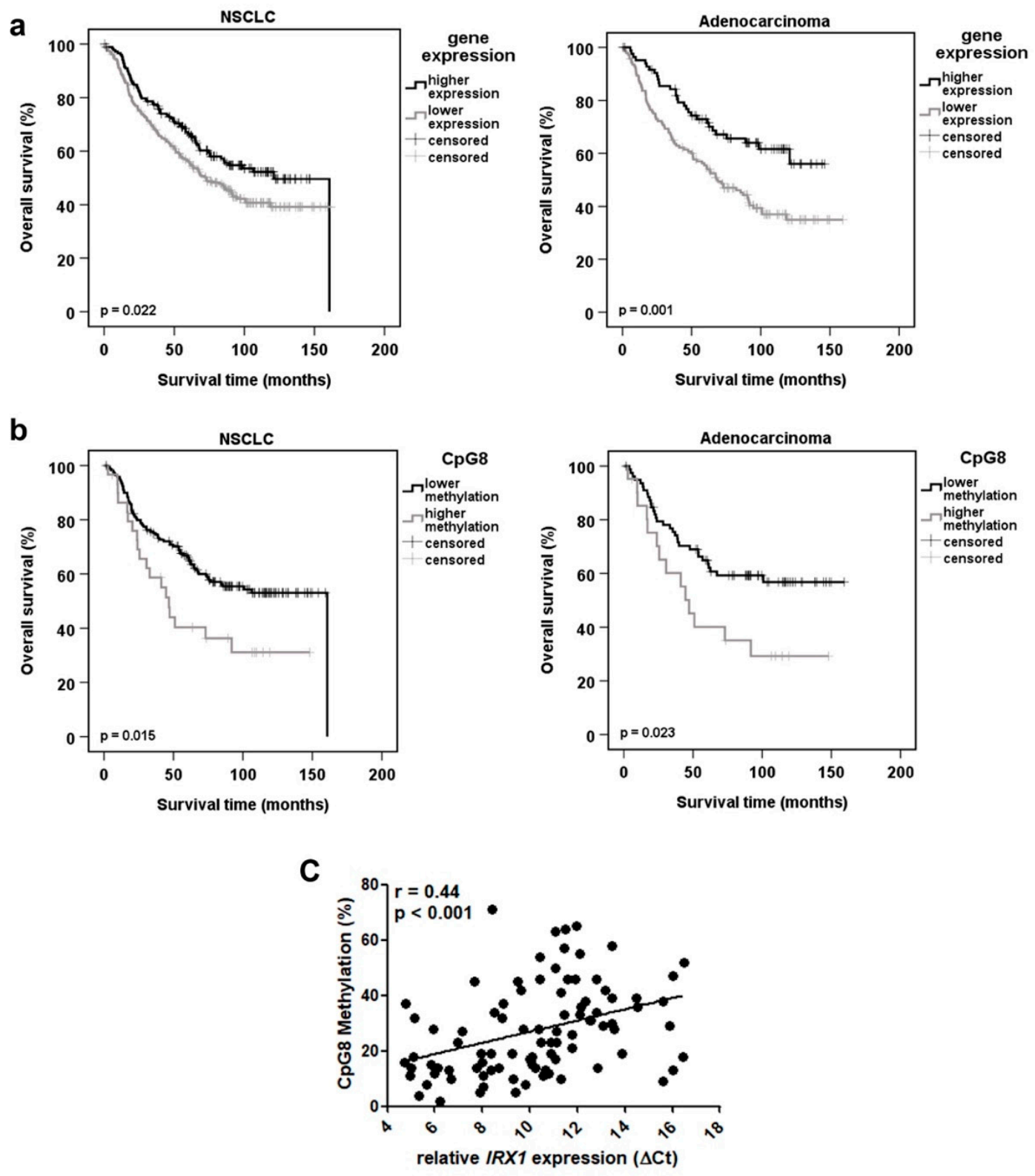

Figure 4. Impaired survival probability of ADC patients is associated epigenetic silencing of IRX1. (a) To correlate high and low IRX1 expression with survival probabilities, we performed the Kaplan-Meier estimator for all patients with non-small cell lung cancer (NSCLC) $(n=416)$ and adenocarcinoma (ADC) $(n=226)$ shown in months. (b). Survival probability of NSCLC and ADC patients $(n=189$ and 91 , respectively) was correlated with IRX1 methylation level at CpG site 8 (CpG8). (c) Correlation analysis of CpG8 methylation and relative IRX1 expression $(p<0.001) . p<0.05$ was considered significant.

\subsection{Downregulation of IRX1 Is Associated with Increased EZH2 and DNMT3A Expression}

The IRX1 gene is located on chromosome 5p15.33 in an $8.6 \mathrm{~kb}$ CpG island flanked by the two CTCF binding sites (CTCFBS; Figure 1b). It has been reported that the CTCC-binding protein (CTCF) acts as a tumor suppressor gene by regulating the expression of tumor-related genes [35]. Epigenetic silencing of several tumor suppressor genes is associated with loss of CTCF binding and loss of its function as a chromatin boundary or insulator [36,37]. CTCF binding is inhibited by DNA methylation 
of its binding site and aberrant methylation of CTCFBS have been reported in human cancer [38-40]. Thus, we analyzed the methylation of the $5^{\prime}$ - and $3^{\prime}$-CTCBS of the IRX1 gene by combined bisulfite restriction analysis (Figure S6). We observed a correlation between methylation of the flanking CTCFBS and IRX1 promoter methylation. In the cancer cell lines SNB18, U343, U251, U118, and T47D on CTCFBS and the IRX1 promoter are unmethylated (Figure S6). In contrast, the other cell lines exhibited hypermethylation of both CTCFBS and of the IRX1 promoter. To analyze the impact of the CTCF binding sites flanking the IRX1 CpG island, we utilized the CRISPR/Cas9 system to delete the $5^{\prime}$ - and/or $3^{\prime}$-CTCFBS in the U251 cell line which expresses IRX1 (Figure 5a).

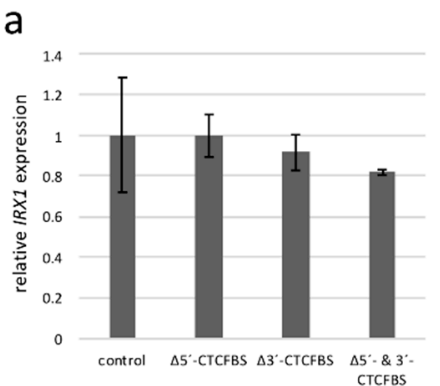

d

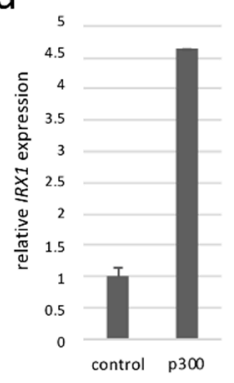

b

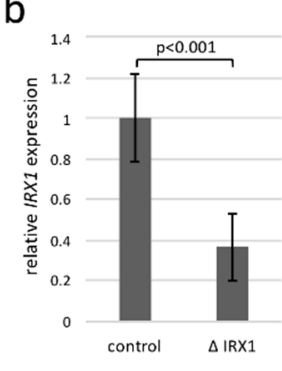

C

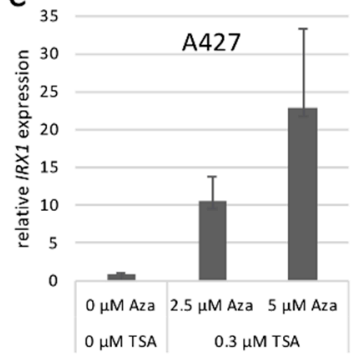

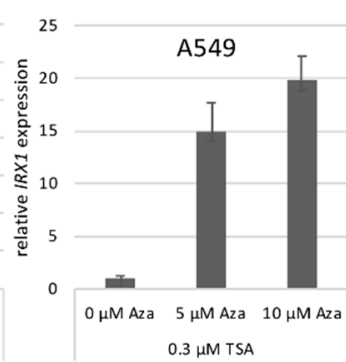

EZH2 (203358_s_at)

g
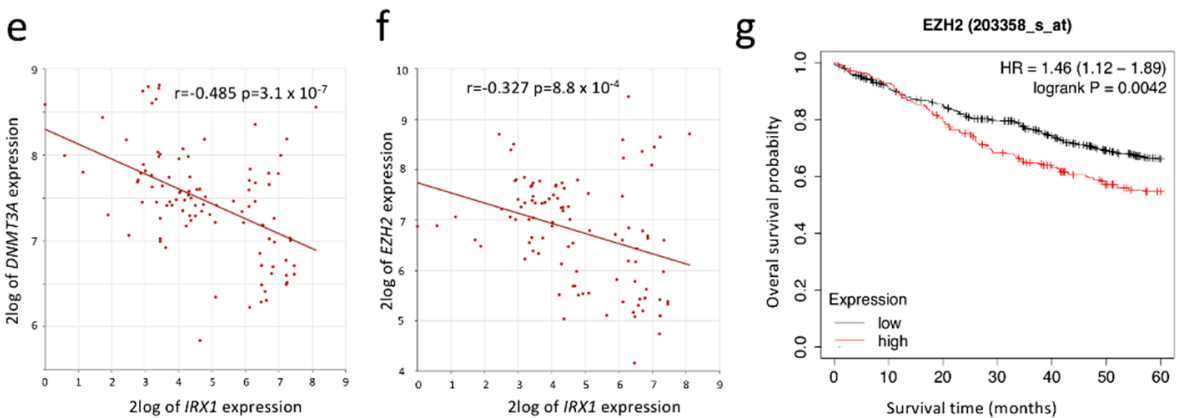

Figure 5. IRX1 is regulated by DNA methyltransferase and p300 HAT activity. (a) Deletion $(\Delta)$ of $5^{\prime}$ - and $3^{\prime}$-CTCF binding site in U251 cell by CRISPR/Cas9 system. We generated two control clones, three $\Delta 5^{\prime}-$ CTCFBS, four $\Delta 3^{\prime}$-CTCFBS, and two $\Delta 5^{\prime}+3^{\prime}$-CTCFBS clones and analyzed IRX1 expression for each clone. RNA levels were determined by qRTPCR in triplicates and normalized to ACTB level. IRX1 expression of control clones was set 1 for comparison. (b) Deletion of the IRX1 promoter ( $\triangle I R X 1)$ by CRISPR/Cas9 system. Expression of IRX1 was analyzed in $13 \triangle \mathrm{IRX} 1$ clones by qRTPCR and normalized to ACTB. $p$-value was calculated by unpaired t-test. (c) A427 and A549 cell lines were treated with the indicated concentration of 5-Aza-2'-deoxycytidine (Aza) and trichostatin A (TSA) for 4 days and RNA was isolated. IRX1 mRNA levels were analyzed in technical triplicates and normalized to ACTB. Then, $0 \mu \mathrm{M}$ Aza treatment was set 1. (d) p300 HAT induced expression of endogenous IRX1. HeLa cells were transfected with IRX1 guide RNA constructs and p300-dCas9 or pcDNA-dCas (control). IRX1 expression was analyzed by qRTPCR after $1 \mu \mathrm{M}$ Aza and $0.3 \mu \mathrm{M}$ TSA treatment for $72 \mathrm{~h}$ and normalized to ACTB levels. (e,f) Correlation analysis of IRX1 and (e) DNMT3A or (f) EZH2 expression in primary NSCLC samples (GSE33532 data set, $n=100$ ). Analysis was performed by R2 [30]. (g) Impaired survival probability of adenocarcinoma patients is associated with high EZH2 expression. Survival probability of ADC patients $(n=719)$ was correlated with EZH2 expression (low and high) through the Kaplan-Meier plotter [33]. $p<0.05$ was considered significant.

We generated two control clones, three $\Delta 5^{\prime}$-CTCFBS, four $\Delta 3^{\prime}$-CTCFBS, and two $\Delta 5^{\prime}+3^{\prime}$-CTCFBS clones and analyzed IRX1 expression (Figure 5a). Deletion of CTCFBS was verified by PCR and conventional sequencing for all clones. IRX1 levels were determined by qRTPCR and plotted relative to the control clones. However, deletion of CTCFBS ( $5^{\prime}$ or/and $\left.3^{\prime}\right)$ showed no significant effect on IRX1 expression (Figure $5 a)$. We also generated a deletion of the IRX1 promoter ( $\triangle \mathrm{IRX} 1$ ) by CRISPR/Cas9 system (Figure $5 b$ ). Expression of IRX1 was investigated in $13 \Delta \mathrm{IRX} 1$ clones and we observed a significant reduction in IRX1 expression compared to controls (2.7-fold median reduction; $p<0.0001$ ). 
To analyze the reactivation of IRX1 expression in lung cancer cell lines, we treated A427 and A549 cells with an inhibitor of DNMT (Aza/5-Aza-2'-deoxytidine) and an inhibitor of HDAC (TSA/trichostatin A) (Figure 5c). Both cell lines were treated with increasing concentration of Aza and $0.3 \mu \mathrm{M}$ TSA. In A427 and A459 lung cancer cell lines, we observed a dosage dependent induction of IRX1 expression by the DNMT inhibitor (20-fold induction by 5 or $10 \mu \mathrm{M}$ Aza, respectively) (Figure $5 \mathrm{c}$ ). Subsequently we investigated the effect of epigenetic editing by promoter specific recruitment (CRISPR/dCas9 system) of histone acetyltransferase p300 HAT to the IRX1 promoter in HeLa cells, that harbor hypermethylated IRX1 promoter (Figure 1d). In this tethering experiment, we revealed that recruitment of p300 HAT to the IRX1 promoter induced the expression of IRX1 4.5-fold compared to the control (Figure 5d). Next, we analyzed the binding of transcriptional regulators to the promoter region of IRX1 by ChIP-seq in the ENCODE data set (Figure S7a). This data revealed that EZH2 binds several positions of the IRX1 promoter region. In lung cancer, overexpression of DNMTs and EZH2 has been reported [3,41,42]. Interestingly, we also observed an inverse correlation between IRX1 expression and DNMT3A or EZH2 levels in primary NSCLC samples (Figure 5e,f, respectively). This significant reduction of IRX1 level associated with higher DNMT3A or EZH2 expression was confirmed in three independent NSCLC data sets (Figure S7b). In order to correlate EZH2 expression with patient survival probabilities, we performed the Kaplan-Meier estimator (Figure 5g). Higher EZH2 level was associated with an impaired survival rate of patients with $\operatorname{ADC}(p=0.0042 ; n=719)$.

By gene ontology analysis, IRX1 expression was also linked to the GO term cell cycle in four NSCLC data sets (Table 1). We also correlated IRX1 expression by gene set enrichment analysis (GSEA) by the Genomics Analysis and Visualization Platform R2 (Table 1). IRX1 expression was significantly, negatively correlated with hallmarks E2F- and Myc-targets, mTORC1 signaling, and G2M checkpoint in these microarrays (Table 1). Additionally, in the data set GSE19804 [43] IRX1 expression was also negatively associated with hallmark EMT $(p=0.00063)$ and positively with myogenesis $(p=0.0013)$. Interestingly, in the TCGA-LUAD data set, IRX1 expression was also significantly correlated with the hallmark p53-pathway (Table 1).

Table 1. Significances of hallmarks correlated with IRX1 expression in NSCLC data sets by gene set enrichment analysis (GSEA).

\begin{tabular}{|c|c|c|c|c|}
\hline Hallmarks ${ }^{1}$ & GSE33532 [44] & GSE19804 [43] & TCGALUAD & GSE63074 [45] \\
\hline E2F_targets ${ }^{2}$ & $1.1 \times 10^{-6}$ & $1.0 \times 10^{-15}$ & $1.7 \times 10^{-19}$ & $6.2 \times 10^{-9}$ \\
\hline Myc_targets_V1 2 & $1.1 \times 10^{-6}$ & $5.2 \times 10^{-3}$ & - & - \\
\hline mTORC1_signaling 2 & $9.2 \times 10^{-5}$ & $1.6 \times 10^{-4}$ & $3.6 \times 10^{-3}$ & $9.0 \times 10^{-3}$ \\
\hline G2M_checkpoint ${ }^{2}$ & $5.6 \times 10^{-4}$ & $1.6 \times 10^{-11}$ & $1.3 \times 10^{-10}$ & $1.4 \times 10^{-4}$ \\
\hline $\mathrm{EMT}^{2}$ & - & $6.3 \times 10^{-4}$ & - & - \\
\hline myogenesis ${ }^{3}$ & - & $1.3 \times 10^{-3}$ & - & - \\
\hline p53_pathway ${ }^{3}$ & - & - & $3.6 \times 10^{-3}$ & - \\
\hline
\end{tabular}

\subsection{Overexpression of IRX1 Is Associated with Fragmented Nuclei and Induction of BAX}

To investigate the cellular function of IRX1, we fused its ORF with an enhanced yellow fluorescent protein (EYFP) and transfected this construct in A549 lung cancer cells (Figure 6). EYFP tagged IRX1 was localized in the nucleus in A549 cells and we noted that IRX1-expressing cells had irregular shapes and fragmented nuclei (Figure 6a). Additionally, we utilized HeLa cancer cells (Figure 6b) and HEK293T cells (Figure 6c) to verify the shape of nuclei upon IRX1 transfection. In both cell lines, we observed a significant accumulation of fragmented nuclei in the IRX1-expressing cells compared to control cells (EYFP). Subsequently, we deleted specific domains of IRX1 (Figure 1), including the homeobox $(\Delta$ Homeo), the HARE-HTH domain $(\Delta$ Hare), and the IRO box ( $\Delta$ Iro) by site directed mutagenesis. We transfected these IRX1-deletion constructs in A549 (Figure 6a), HeLa (Figure 6b), and HEK293 cells (Figure 6c) and analyzed the localization of these proteins. 

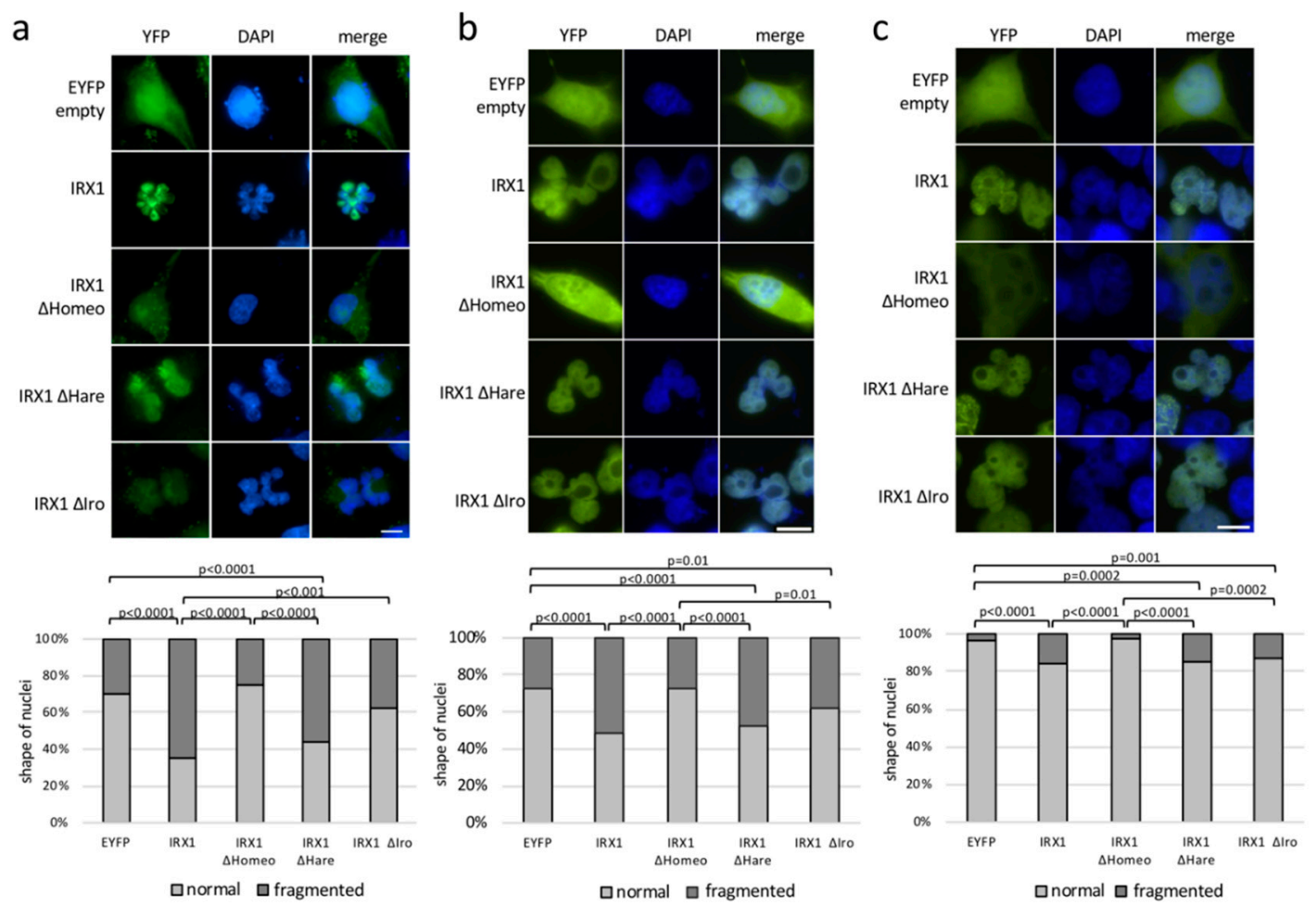

Figure 6. Nuclear localization of IRX1 and irregular shape of IRX1 expressing nuclei. IRX1 was fused to EYFP and transfected in A549 (a) HeLa (b) and HEK293T (c) cells. Localization of IRX1 in the nucleus was analyzed by DAPI co-staining and fluorescent microscopy. IRX1 deletion construct of homeobox ( $\Delta$ Homeo), HARE-HTH domain $(\Delta$ Hare), and IRO box ( $\Delta$ Iro) were generated and transfected. The nuclear shape of transfected cells was analyzed after $24 \mathrm{~h}$ in A549 (80-160 cells analyzed), HeLa (200-350 cells), and HEK293 (150-300 cells). Normal nuclei exhibited a round shape and fragmented nuclei showed an irregular, lobed shape. Significance was calculated by Fisher's exact test. White bar represents the length standard of $5 \mu \mathrm{M}$.

Interestingly, we observed that the IRX1- $\Delta$ Homeo protein exhibited a similar localization as control EYFP transfected cells and that the induction of fragmented nuclei was significantly associated with the presence of the IRX1 homeobox (Figure 6). This indicates that the homeobox is an important functional domain of IRX1 and responsible for the nuclear localization. $\Delta$ Homeo- and $\Delta$ Iro-IRX1 constructs showed a nuclear localization and also induced fragmented nuclei in all three cell lines. However, in A549 cells, $\triangle$ Iro-IRX1 induced significantly fewer fragmented nuclei compared to full length IRX1 (Figure 6a). Subsequently, we analyzed the effect of IRX1 expression on the apoptosis regulator Bcl2-associated X (BAX) (Figure 7). Therefore, we transfected IRX1 in cancer cells and analyzed the mRNA levels of $B A X$ (Figure 7a). Compared to the control cells, we observed a 4-fold induction of $B A X$ in the IRX1 expressing HeLa cells. However, in IRX1- $\triangle$ Homeo overexpressing cells, $B A X$ induction was reduced to only 2-fold. BAX mRNA levels, in cells transfected with the deletion constructs of the HARE-HTH domain $(\triangle$ Hare) or the IRO box $(\triangle \mathrm{Iro})$, were comparable to full length IRX1 (Figure $7 \mathrm{a})$.

We also analyzed the expression values of BAX in IRX1-expressing HEK293T cells by GEO2R [46,47]. A 1.7-fold induction of IRX1 was revealed in the data set GSE75376 (Figure S8). IRX1 expression was associated with a 3.2-fold induction of BAX values compared to control transfected HEK293T cells (Figure 7b). Additionally, the effect of IRX1-knock down (shIRX) was investigated in 143B osteosarcoma cells [48] (Figure 7c). Compared to control-knock down (shCtrl), IRX1 levels were 2-fold reduced in the shIRX1 cells (Figure S8). Knock down of IRX1 (shIRX1) resulted in reduced BAX levels compared to 143B-shCtrl cells. This data indicates that IRX1 levels are linked with the expression of the apoptosis regulator BAX. 
a

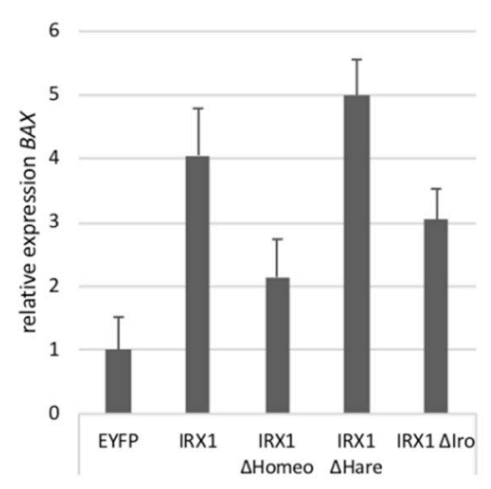

b

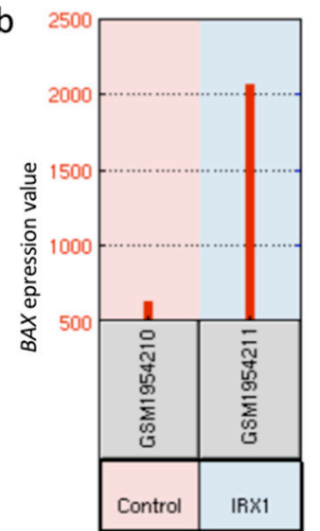

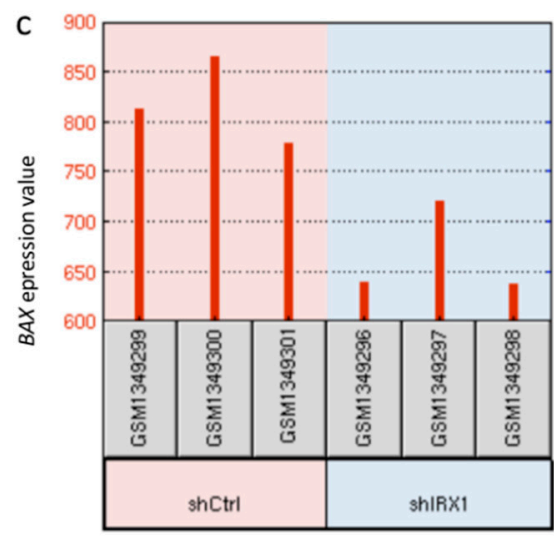

Figure 7. IRX1 expression is associated with expression of the apoptotic regulator BAX. (a) IRX1 wt and IRX1 deletion construct of homeobox ( $\triangle$ Homeo), HARE-HTH domain $(\triangle$ Hare), and IRO box $(\triangle \mathrm{Iro})$ were transfected in HeLa cells. RNA was isolated after $48 \mathrm{~h}$ and $B A X$ mRNA levels were analyzed in technical triplicates and normalized to ACTB. BAX expression was plotted relative to EYFP-control transfected HeLa cells (set = 1). (b) BAX expression values (208478_s_at) were analyzed in pcDNA3.1-GFP (control) and pcDNA3.1-IRX1-GFP transfected HEK293T cells in the data set GSE75376 by GEO2R [46,47]. (c) Expression of BAX (NM_004324) was analyzed in 143B cells after IRX1 (shIRX1) and control (shCtrl) knock down in technical triplicates in the data set GSE56255 by GEO2R [47,48].

\section{Discussion}

In our study, we wanted to understand the regulation of IRX1 in lung cancer and its molecular contribution to tumorigenesis. IRX1 is localized on cytoband $5 \mathrm{p} 15.33$ and it has been reported that this region harbors a susceptibility locus for lung cancer [21-23]. Here, we show that IRX1 is expressed in normal lung tissue (Figure S1a) and downregulated in NSCLC tumors (Figure 3). Additionally, we revealed that the reduced expression of IRX1 in cancer is linked to its promoter hypermethylation (Figures 2 and $4 \mathrm{c})$. In normal lung, the IRX1 promoter exhibits low methylation $(<10 \%)$ and this result has been found for two CpG sites by $450 \mathrm{~K}$ bead chip (Figure 2) and for nine CpGs by bisulfite pyrosequencing (Figure 3b). The third 450K CpG probe (cg09232937) exhibits, in general, a higher methylation level in normal lung, but also in cancer cell lines (Figure 2 and Figure S3). It would be interesting to verify the methylation level of this specific $\mathrm{CpG}$ site by conventional bisulfite sequencing. However, this genomic region is very $\mathrm{CpG}$ - and GC-rich and therefore difficult to sequence (Figure 1c).

For gastric cancer, an SNP (rs11134044) has been associated with differential expression of IRX1 and correlated with cancer risk by a genome-wide association study (GWAS) [49]. Interestingly, this SNP is located $700 \mathrm{~kb}$ downstream of the IRX1 gene and this region could harbor an IRX1 enhancer. A lung cancer associated risk of the biomarker rs 11134044 has been not reported by GWAS. Regulation of gene activity though distal enhancers are often linked to genomic CTCF binding sites (CTCFBS) and methylation of these sites block CTCF binding [50,51]. Epigenetic alteration or mutation of CTCFBS have been associated with deregulation of tumor suppressor genes [36-38,52]. Here, we observed a link between methylation of the CTCFBS flanking the $5^{\prime}$ - and $3^{\prime}$-shore of the IRX1 CpG island and the methylation of the IRX1 promoter (Figure S6). Therefore, we deleted the two CTCF consensus sites by CRISPR/Cas9 technology and analyzed the expression of IRX1. Deletion of both CTCFBS resulted only in a mild reduction of $I R X 1 \mathrm{mRNA}$ levels, compared to the proximal IRX1 promoter deletion (Figure 5).

In lung cancer, overexpression of DNMTs and EZH2 has been reported [3,41,42]. EZH2 is histone H3 lysine 27 methyltransferase and the catalytic subunit of the transcriptional repressive complex of PRC2. ChIP-seq data revealed frequent binding of EZH2 to a $3 \mathrm{~kb}$ sequence flanking the transcriptional start site of the IRX1 gene (Figure S7a). EHZ2 directly controls DNA methylation through interaction with DNMTs [53]. This data suggests that IRX1 is an EZH2-target promoter and EZH2 may act as a recruitment platform for de novo methyltransferase DNMT3A [53]. Subsequently, we analyzed 
the correlation of IRX1 expression and levels of DNMT3A and EZH2 (Figure 5e,f and Figure S7b). Here, we observed an inverse correlation of IRX1 and DNMT3A or EZH2 expression in primary lung cancers suggesting a causal relation between aberrant expression of epigenetic modifiers and IRX1 silencing. We also found that high EZH2 level are associated with an impaired prognosis of patients with lung adenocarcinomas (Figure 5g). Moreover, we recruited the p300 HAT to the IRX1 promoter in HeLa cells (Figure 5d) and observed a 4.5-fold induction of endogenous IRX1 level. Interestingly, we observed that IRX1 was already downregulated in cancer cell lines that exhibited only low methylation levels (Figure $2 b$ ). It is tempting to speculated that repressive histone marks (deacetylation and methylation) and precedes DNA hypermethylation of the IRX1 promoter as previously reported for the epigenetic downregulation of RASSF1A tumor suppressor gene [54]. Additionally, inhibition of DNMT activity by 5-Aza-2'-deoxycytidine reactivated the expression of IRX1 in two lung cancer cell lines (Figure 5c). It will be interesting to analyze the exact role of DNMT3A and EZH2 in the epigenetic regulation of $I R X 1$ in lung carcinogenesis.

Since there is evidence that epigenetic control plays a significant role in the pathogenesis of another lung disease (IPAH) [55], we also analyzed IRX1 hypermethylation in IPAH samples. However, low methylation level $(<10 \%)$ were observed in IPAH tissues (Figure S2) and this indicates that DNA hypermethylation of IRX1 is rather associated with lung cancer than with IPAH. In primary SCLC samples IRX1 exhibits also low median methylation (6\%), but some SCLC tissues and cell lines showed high methylation levels (>50\%; Figures $1 \mathrm{~d}$ and 3a). Thus, aberrant IRX1 methylation in SCLC is rather heterogenous compared to NSCLC samples. In adenocarcinoma (ADC), we observed frequent increased methylation of the IRX1 promoter and reduced RNA levels (Figure 3). This epigenetic inactivation of $I R X 1$ was significantly correlated with a reduced survival probability on RNA and DNA methylation levels (Figure 4). These results that low expression and high methylation of IRX1 are associated with an impaired prognosis of ADC patients were also verified in independent data sets (Figures S4 and S5, respectively). Guo et al. analyzed the prognostic value of IRX1 methylation in squamous cell carcinoma of the lung (LUSQ) and reported that methylation of two CpG sites are significantly associated with the prognosis of LUSQ patients [18]. In our experiments, we also observed epigenetic inactivation of IRX1 in SQCC, but the reduced IRX1 level and higher IRX1 methylation were less pronounced compared to ADC (Figure 3). Therefore, we could not reveal such a prognostic value of aberrant IRX1 expression or methylation in SQCC (Figure S4). Yu et al. observed that IRX1 regulates the epithelial differentiation of lung alveolar type II cells [10]. In patients, adenocarcinomas often stain positively with antibodies to markers of the alveolar type II cells and this led to hypothesis that alveolar type II cells could be cells of origin in ADC [56]. Thus, it will be interesting to decipher the functional differences of IRX1 in pathogenesis of ADC compared to SQCC and to analyze the expression of IRX1 in progenitor cells of the lung.

Hypermethylation of IRX1 has been found in gastric cancer [15] or head and neck squamous carcinoma [16]. In gastric cancer, IRX1 acts a tumor suppressor through downregulation of BDKRB2, FGF7, and HIST2H2BE expression and inhibiting angiogenesis and cell proliferation [15]. Consequently, restoring IRX1 expression in two gastric cancer cell lines inhibited growth, invasion, and tumorigenesis in vitro and in vivo [15]. Here, we report that IRX1 expression is negatively correlated with the hallmark EMT a lung cancer data set (Table 1). In head and neck squamous carcinoma cells, overexpression of IRX1 resulted in decreased mitotic activity and increased apoptosis [57]. In our study, we analyzed the localization of IRX1 and we found that overexpression of IRX1 induced fragment nuclei in lung adenocarcinoma cells (Figure 6a). Additionally, we revealed that IRX1 induced the expression of the proapoptotic regulator $B A X$ that is also a p53 target gene (Figure 7). This data suggests that $I R X 1$ is positively associated with the p53 pathway and this has been confirmed by GSEA in the TCGA-LUAD data set (Table 1). Kühn et al. demonstrated that IRX1 overexpression in HEK293 cells is positively associated with GO term apoptosis [46] and in this data set we confirmed induction of $B A X$ through IRX1 (Figure $7 \mathrm{~b}$ ). Interestingly, the induction of $B A X$ and fragmented nuclei by IRX1 relied on the presence of its homeobox (Figures 6 and 7a). Homeobox domains are characteristic protein folds 
that bind DNA and regulate the expression of target genes during development and differentiation. Jung et al. analyzed the function of IRX1 in the development of zebrafish and they demonstrated that IRX1 acts a tumor suppressor in multiple organs by regulating the cell cycle progression [20]. Here, we revealed by GSEA that IRX1 expression is negatively correlated with E2F- and Myc-targets in several lung cancer data sets (Table 1). In general, E2F- and Myc-targets are pro-proliferative factors that induce cell cycle progression and both factors are inhibited by tumor suppressors.

In summary, our data suggest that IRX1 acts as tumor suppressor gene in the pathogenesis of lung adenocarcinoma and epigenetic silencing of IRX1 is associated with advanced stage and impaired prognosis of ADC patients.

\section{Materials and Methods}

\subsection{Cell lines, Lung Cancer Tissues, and Controls}

NSCLC cell lines (A427, A549, H322, H358, and HCC15) and SCLC cell lines (HTB171, HTB175, SLC21H, SCLC22H, SCLC24H, H82, HTB187, H209, H510, H1092, and H1184) were described previously $[4,58]$. Patient samples were provided by Lungbiobank Heidelberg, a member of the Biomaterialbank Heidelberg (BMBH) and the Biobank Platform of the German Centre For Lung Research (DZL) [59] or characterized previously [3,4]. Clinicopathological data of patients with NSCLC are listed in Table S1. All patients signed informed consent at initial clinical investigation. The study was approved by local ethic committees.

\subsection{Cell Culture and Treatment of Cell Lines}

Cell lines were grown in appropriate medium (DMEM/Dulbecco's modified Eagle's medium, RPMI/Roswell Park Memorial Institute) supplemented with $10 \%$ fetal calf serum and $1 \%$ penicillin/streptomycin under cell culture conditions $\left(37^{\circ} \mathrm{C}, 5 \% \mathrm{CO}_{2}\right)$. For 5-Aza-2'-deoxycytidine (Aza, Sigma, Darmstadt, Germany) and trichostatin A (TSA, Sigma, Darmstadt, Germany) treatment cells were split to $10 \%$ density. Then, 2.5, 5, or $10 \mu \mathrm{M}$ Aza and $0.3 \mu \mathrm{M}$ TSA were added with fresh medium on 4 consecutive days before RNA isolation. Cell lines were transfected for indicated time points using polyethylenimine (PEI, $4.9 \mathrm{mM}$, Sigma, Darmstadt, Germany) for HEK293T, Turbofect (Thermo Fisher Scientific, Waltham, MA, USA) for A549, A427, and HeLa or X-tremeGENE HP (Roche, Basel, Switzerland) for U251 according to the manufacturer's protocol with $4 \mu \mathrm{g}$ DNA ( 6 well plates) or $10 \mu \mathrm{g}$ DNA (10-cm dishes).

\subsection{DNA Isolation and Methylation Analysis}

Primers for bisulfite treated DNA were designed to bind only fully converted DNA and amplify $I R X 1$ promoter region. DNA methylation of the IRX1 promoter was analyzed by combined bisulfite restriction analysis (CoBRA) or pyrosequencing [60]. DNA isolation was done after proteinase K (Thermo Fisher Scientific, Waltham, MA, USA) digest, extracted with phenol/chloroform and concentrations were determined by UV-photospectrometery. For cell line COBRA methylation analysis, $2 \mu \mathrm{g}$ genomic DNA was bisulfite treated $(12 \mu \mathrm{L} 0.1$ M hydroquinone, $208 \mu \mathrm{L} 1.9$ M sodium metabisulfite, and pH 5.5 with $\mathrm{NaOH}$ ) and incubated over night at $50{ }^{\circ} \mathrm{C}$. DNA was purified using MSB Spin PCRapace (STRATEC Molecular), eluted in $50 \mu \mathrm{L} \mathrm{H}_{2} \mathrm{O}$, and followed by 10 min incubation with $5 \mu \mathrm{L}$ $3 \mathrm{M} \mathrm{NaOH}$ at $37^{\circ} \mathrm{C}$. DNA was then precipitated with $100 \%$ ethanol and $7.5 \mathrm{M}$ ammonium acetate and resolved in $1 \times$ TE buffer. For patient CoBRA methylation analysis, $250 \mathrm{ng}$ genomic DNA was bisulfite treated using EZ DNA methylation-lightning (Zymo Research, Freiburg, Germany). The CoBRA PCR was performed semi-nested with upper primer 1 TAAATTYGGTGTTAGATAGTTGTAAATT and lower primer 1 AAACTTTCAAACACAATTTAAAATTA, and upper primer 1 and lower primer 2 TAATACTTTAATTAACATCCCCTTAA. The semi-nested PCR product for IRX1 is $272 \mathrm{bp}$ (TaqI digest products of 33, 74, and $165 \mathrm{bp}$ ). The subsequent PCR product was digested with $5 \mathrm{U}$ of TaqI (Thermo Fisher Scientific, Waltham, MA, USA) $1 \mathrm{~h}$ at $65^{\circ} \mathrm{C}$ and resolved on $2 \%$ TBE gel together with mock control and 
DNA ladder. In vitro methylation (ivm) of genomic DNA was performed using CpG Methyltransferase M.SssI (NEB, Frankfurt, Germany) according to manufacturer's protocol. Pyrosequencing was performed according to manufacturer's protocol with PyroMark Q24 System (Qiagen, Hilden, Germany), biotinylated lower primer 2, and sequencing primer GGTTTTYGGGTTTATATTT.

\subsection{Patient Biospecimen}

This biomarker study was conducted in accordance with the Reporting Recommendations for Tumor Marker Prognostic Studies [61]. Tissue samples were provided by the Lung Biobank Heidelberg, a member of the accredited Tissue Bank of the National Center for Tumor Diseases (NCT) Heidelberg, the Biomaterial Bank Heidelberg, and the Biobank platform of the German Center for Lung Research (DZL). The use of biomaterial and data for this study was approved by the local ethics committee of the Medical Faculty Heidelberg (S-270/2001). All patients included in the study signed an informed consent and the study performed according to the principles set out in the WMA Declaration of Helsinki. Tumor and matched distant $(>5 \mathrm{~cm})$ normal lung tissue samples from patients with NSCLC who underwent therapy-naive resection for primary lung cancer at Thoraxklinik at University Hospital Heidelberg, Germany were collected between 2006 and 2011. Tissues were snap-frozen within $30 \mathrm{~min}$ after resection and stored at $-80^{\circ} \mathrm{C}$ until the time of analysis. More detailed information is described elsewhere [59].

Human lung tissue explanted from patients with PAH was obtained during lung transplantation. Similarly, donor lung samples obtained from downsized healthy lung tissues to serve as a reference to PAH samples. The study protocol for tissue donation was approved by the Ethics Committee (Ethik Kommission am Fachbereich Humanmedizin der Justus Liebig Universität Giessen) of the University Hospital of Giessen, Germany, in accordance with national law and Good Clinical Practice/International Conference on Harmonisation guidelines. Written informed consent was obtained from individual patients or the patient's next of kin (AZ 31/93).

\subsection{RNA Expression Analysis}

RNA from human cell culture was isolated using Isol-RNA lysis procedure (Trizol, Thermo Fisher Scientific, Waltham, MA, USA). RNA was DNase (Thermo Fisher Scientific, Waltham, MA, USA) treated and then reversely transcribed by MMLV (Promega, Madison, WI, USA). Quantitative RT-PCR was performed in triplicate with SYBR select (Thermo Fisher Scientific, Waltham, MA, USA) using Rotor-Gene 3000 (Qiagen, Hilden, Germany). The following primers were used for qPCR: IRX1RTF1 (GCGGATCTCAGCCTCTTCTCG), IRX1RTL4 (GGGGTCCCCGTATTGGAACT), BAXRTR (CGCGGTGGTGGGGGTGAGG), BAXRTF (AACTGGGGCCGGGTTGTCGC), BACTRTFW (CCTTCCTTCCTGGGCATGGAGTC), BACTRTRV (CGGAGTACTTGCGCTCAGGAGGA).

For RNA isolation from patient tumor tissue, a tumor content of $\geq 50 \%$ was the minimum prerequisite. A total of 10-15 tumor cryosections $(10-15 \mu \mathrm{M})$ from each patient were sliced, and the first as well as the last section of the series was stained with H\&E. A lung pathologist determined the proportion of viable tumor cells, stromal cells, healthy lung cells, and necrotic areas. Total RNA was isolated from patient tissue using an AllPrep DNA/RNA/miRNA Universal kit (Qiagen, Hilden, Germany) according to the manufacturer's instructions. A RNeasy Mini kit (Qiagen, Hilden, Germany) was used to isolate RNA from the cell lines. Afterwards, the quality of total RNA was assessed by utilizing an Agilent 2100 Bioanalyser and an Agilent RNA 6000 Nano kit (Agilent Technologies, Boeblingen, Germany). With the Transcriptor First Strand cDNA Synthesis kit (Roche, Basel, Switzerland), total RNA was transcribed to complementary DNA and used for quantitative polymerase chain reaction (qPCR). A complete description of the procedure is provided elsewhere [62]. For gene expression analyses of patient tissues, volumes of $5 \mu \mathrm{L}$ cDNA (corresponding to $5 \mathrm{ng}$ of isolated total RNA) were utilized for qPCR with the LightCycler480 (Roche, Basel, Switzerland) in 384-well plates according to the Minimum Information for Publication of qPCR Experiments (MIQE) guidelines [63]. Universal probe library (UPL) assay (Roche, Basel, Switzerland) was used as the amplification and detection system. Gene-specific primers (TIB Molbiol, Berlin, Germany) were combined with the primaQuant $2 \times q P C R$ 
Probe-MasterMix (Steinbrenner Laborsysteme, Wiesenbach, Germany). Threshold cycle (Ct) values were evaluated with the LightCycler480 ${ }^{\circledR}$ software release 1.5 and the 2 nd derivative maximum method (Roche, Basel, Switzerland). For the comparison of gene expression in tumor and non-malignant samples, the relative expression of the genes (normalized to the housekeepers Esterase $D(E S D)$ and Ribosomal Protein S18 (RPS18)) was calculated ( $\triangle \mathrm{Ct}$ values). The following primers and UPL were used for the detection of IRX1: IRX1 forward (UPL\#66, GGGCACTCAATGGAGACAA), IRX1 reverse (UPL\#66, CTGGGGACGAGGTCTCTCT), ESD forward (UPL\#50, TCAGTCTGCTTCAGAACATGG), ESD reverse (UPL\#50, CCTTTAATATTGCAGCCACGA), RPS18 forward (UPL\#46, CTTCCACAGGAGGCCTACAC), RPS18 reverse (UPL\#46, CGCAAAATATGCTGGAACTTT).

\subsection{Plasmids}

The full length IRX1 coding sequence (BC166635) was obtained from BioCat (Heidelberg, Germany) and cloned into pEYFP (Clontech, Saint-Germain-en-Laye, France). IRX1 domains were deleted by site-directed mutagenesis (QuikChange Lightning, Agilent, Boeblingen, Germany) and verified by sequencing and fluorescence microscopy. Oligos for mutagenesis were $\triangle$ Homeobox: CAGCACGCTCAAGGCCCTCAAGAAGGAGAACAA and TTGTTCTCCTTCTTGAGGGCCTTGAGCGTGCTG, $\triangle$ HARE-HTH: GGCGCCTCAAGAAGAAGGCCGAGGCTCC and GGAGCCTCGGCCTTCTTCTTGAGGCGCC and $\triangle$ Irobox: GGCGCACCGTCGCCGTGCGGCG and CGCCGCACGGCGACGGTGCGCC.

\subsection{Genetic and Epigenetic Editing}

Cas9 vector px549 (SpCas9-2A-PuroV2.0, Addgene, Watertown, USA) was obtained from Lienhard Schmitz (Giessen, Germany) and adapted for epigenetic editing. The IRX1 and CTCFBS targeting guide RNAs were cloned into px549 under U6 promoter. Single oligos for IRX1 RNA guides for promoter deletion are \#1 CGCTCCTCCCTAGACCCCTCG and \#2 CCGCAGTCGGCGCGCGAT and are positioned relative to TSS at $-61 \# 1$ and $-185 \# 2$, respectively. Oligos for RNA guides for the deletion of 5'-CTCFBS motif (hg19: chr5:3,594,998-3,595,024) are CGCCGCCGCCAGACCGGCAA and GAGAAGAGGGACGCGGGACT and for deletion of 3'-CTCFBS motif (hg19: chr5:3,603,194-3,603,218) are AGTCGGAATGGACGTGCTCC and TCAAGGCCGCATTCCGCTTT. We transfected U251 cells with the Cas9 $\triangle I R X 1$ - or $\triangle$ CTCFBS-guide constructs and selected for positive clones by puromycin $(1 \mu \mathrm{g} / \mathrm{mL})$ for three days. Clones were expanded and the knockout was verified by PCR based amplification of the flanking genomic region and conventional sequencing.

For epigenetic editing, px549 was adapted by deletion of Cas9. IRX1 RNA guides for promotor reporter assay are \#1, \#3 CGCGACCGGCCTCCATC (-166), \#5 TTGCCGGTCTGGCGGCGGCGC (-1201), and \#6 GAGAAGAGGGACGCGGGACT (positioned -1242). p300 (pcDNA-dCas9-p300 Core, Addgene, Watertown, USA) was used as epigenetic modifier upon co-transfection in HeLa cells [64].

\subsection{Fluorescent Microscopy}

For morphological analysis, cells were seeded on glass slides and transfected the following day. Cells were fixed with 3.7\% formaldehyde at according time points, permeabilized using TritonX, stained with DAPI $(0.1 \mu \mathrm{g} / \mathrm{mL}$ in PBS, Sigma, Darmstadt, Germany), embedded in anti-fading with Mowiol (Sigma, Darmstadt, Germany) and analyzed with Axio Observer Z1 (Zeiss, Oberkochen, Germany) under $\times 63$ magnification and Velocity Software (Perkin Elmer, Waltham, MA, USA).

\subsection{Data and Statistical Analysis}

Gene expression analysis, promoter methylation correlation, and Kaplan-Meier calculations were performed using Genomics Analysis and Visualization Platforms: R2 [30], Wanderer [32], GTEx [25], KM Plotter [33], GEO2R [47] and MethSurv [34]. 


\section{Conclusions}

Lung cancer incidences are growing and therefore the requirement for novel treatment options and detection methods are rising. In our work, we identified Iroquois homeobox 1 (IRX1) from the lung cancer susceptibility locus 5p15.33, as an epigenetically silenced target gene. We also analyzed the regulation of $I R X 1$ as a potential target for lung cancer diagnosis and its reactivation as a novel therapeutic option for epigenetic editing. We are showing that inactivation of IRX1 is linked to aberrant expression of DNMT3A and EZH2 and that inhibition of DNMT and HDAC induces IRX1 expression. Additionally, we validated the IRX1 promoter as a target for epigenetic editing. We are also showing that IRX1 expression is negatively associated with oncogenic hallmarks by GSEA and that IRX1 expression induces signs of apoptosis in cancer cells, including fragmented nuclei and $B A X$ levels. In different datasets, we could validate that epigenetic silencing of $I R X 1$ is clinically correlated with impaired survival and with progressed disease state of lung adenocarcinoma patients. Thus, loss of IRX1 expression by its promoter hypermethylation can serve as a diagnostic and prognostic lung cancer biomarker.

Supplementary Materials: The following are available online at http://www.mdpi.com/2072-6694/12/12/3528/s1, Figure S1: Expression of IRX1 in normal tissues and cancer cell lines; Figure S2: IRX1 promotor methylation of 9 analyzed CpG sites in NSCLC and IPAH patients; Figure S3: Methylation and expression of IRX1 in ADC (LUAD) and SQCC (LUSQ); Figure S4: Impaired survival probability of adenocarcinoma patients and advanced tumor stages are associated with low IRX1 expression; Figure S5: Impaired survival probability of NSCLC patients is associated higher IRX1 methylation; Figure S6: Methylation analysis of the IRX1 5' - and 3'-CTCF binding sites in cancer cell lines; Figure S7: Regulation of IRX1 by EZH2 and DNMT3A; Figure S8: IRX1 expression after IRX1 transfection in HEK293T cells and IRX1 knock down in osteosarcoma 143B cells; Table S1: Summary of clinicopathological data of NSCLC patients.

Author Contributions: R.H.D. conceived and designed the study. M.M.K., M.A.S., S.R. and A.M.R. performed experiments. M.A.S., H.W., M.K., S.S.P., T.S., R.S. and T.M. contributed research materials. M.M.K., M.A.S., S.R., T.M. and R.H.D. analyzed data. R.H.D. wrote the manuscript. All authors have read and agreed to the published version of the manuscript.

Funding: This research was funded by the German Center for Lung Research (82DZL00402).

Acknowledgments: We thank Sara Walesch, Christa Stolp, Martin Fallenbuechel and Andrea Bopp for technical support.

Conflicts of Interest: The authors declare no conflict of interest. The funders had no role in the design of the study; in the collection, analyses, or interpretation of data; in the writing of the manuscript or in the decision to publish the results.

\section{References}

1. Ferlay, J.; Soerjomataram, I.; Dikshit, R.; Eser, S.; Mathers, C.; Rebelo, M.; Parkin, D.M.; Forman, D.; Bray, F. Cancer incidence and mortality worldwide: Sources, methods and major patterns in GLOBOCAN 2012. Int. J. Cancer 2015, 136, E359-E386. [CrossRef] [PubMed]

2. Dammann, R.; Li, C.; Yoon, J.H.; Chin, P.L.; Bates, S.; Pfeifer, G.P. Epigenetic inactivation of a RAS association domain family protein from the lung tumour suppressor locus 3p21.3. Nat. Genet. 2000, 25, 315-319. [CrossRef] [PubMed]

3. Kiehl, S.; Zimmermann, T.; Savai, R.; Pullamsetti, S.S.; Seeger, W.; Bartkuhn, M.; Dammann, R.H. Epigenetic silencing of downstream genes mediated by tandem orientation in lung cancer. Sci. Rep. 2017, 7, 3896. [CrossRef] [PubMed]

4. Richter, A.M.; Kiehl, S.; Koger, N.; Breuer, J.; Stiewe, T.; Dammann, R.H. ZAR1 is a novel epigenetically inactivated tumour suppressor in lung cancer. Clin. Epigenetics 2017, 9, 60. [CrossRef] [PubMed]

5. Gomez-Skarmeta, J.L.; Modolell, J. Iroquois genes: Genomic organization and function in vertebrate neural development. Curr. Opin. Genet. Dev. 2002, 12, 403-408. [CrossRef]

6. Kim, K.H.; Rosen, A.; Bruneau, B.G.; Hui, C.C.; Backx, P.H. Iroquois homeodomain transcription factors in heart development and function. Circ. Res. 2012, 110, 1513-1524. [CrossRef]

7. Leyns, L.; Gómez-Skarmeta, J.-L.; Dambly-Chaudière, C. iroquois: A prepattern gene that controls the formation of bristles on the thorax ofDrosophila. Mech. Dev. 1996, 59, 63-72. [CrossRef] 
8. Hu, W.; Xin, Y.; Zhang, L.; Hu, J.; Sun, Y.; Zhao, Y. Iroquois Homeodomain transcription factors in ventricular conduction system and arrhythmia. Int. J. Med. Sci. 2018, 15, 808-815. [CrossRef]

9. Cavodeassi, F.; Modolell, J.; Gomez-Skarmeta, J.L. The Iroquois family of genes: From body building to neural patterning. Development 2001, 128, 2847-2855.

10. Yu, W.; Li, X.; Eliason, S.; Romero-Bustillos, M.; Ries, R.J.; Cao, H.; Amendt, B.A. Irx1 regulates dental outer enamel epithelial and lung alveolar type II epithelial differentiation. Dev. Biol. 2017, 429, 44-55. [CrossRef]

11. Lu, Y.; Yu, Y.; Zhu, Z.; Xu, H.; Ji, J.; Bu, L.; Liu, B.; Jiang, H.; Lin, Y.; Kong, X.; et al. Identification of a new target region by loss of heterozygosity at 5 p15.33 in sporadic gastric carcinomas: Genotype and phenotype related. Cancer Lett. 2005, 224, 329-337. [CrossRef] [PubMed]

12. Arias-Pulido, H.; Narayan, G.; Vargas, H.; Mansukhani, M.; Murty, V.V. Mapping common deleted regions on 5p15 in cervical carcinoma and their occurrence in precancerous lesions. Mol. Cancer 2002, 1, 3. [CrossRef] [PubMed]

13. Xu, S.F.; Peng, Z.H.; Li, D.P.; Qiu, G.Q.; Zhang, F. Refinement of heterozygosity loss on chromosome 5p15 in sporadic colorectal cancer. World J. Gastroenterol. 2003, 9, 1713-1718. [CrossRef] [PubMed]

14. Wieland, I.; Bohm, M.; Arden, K.C.; Ammermuller, T.; Bogatz, S.; Viars, C.S.; Rajewsky, M.F. Allelic deletion mapping on chromosome 5 in human carcinomas. Oncogene 1996, 12, 97-102.

15. Guo, X.; Liu, W.; Pan, Y.; Ni, P.; Ji, J.; Guo, L.; Zhang, J.; Wu, J.; Jiang, J.; Chen, X.; et al. Homeobox gene IRX1 is a tumor suppressor gene in gastric carcinoma. Oncogene 2010, 29, 3908-3920. [CrossRef]

16. Bennett, K.L.; Karpenko, M.; Lin, M.T.; Claus, R.; Arab, K.; Dyckhoff, G.; Plinkert, P.; Herpel, E.; Smiraglia, D.; Plass, C. Frequently methylated tumor suppressor genes in head and neck squamous cell carcinoma. Cancer Res. 2008, 68, 4494-4499. [CrossRef]

17. Kitchen, M.O.; Bryan, R.T.; Emes, R.D.; Glossop, J.R.; Luscombe, C.; Cheng, K.K.; Zeegers, M.P.; James, N.D.; Devall, A.J.; Mein, C.A.; et al. Quantitative genome-wide methylation analysis of high-grade non-muscle invasive bladder cancer. Epigenetics 2016, 11, 237-246. [CrossRef]

18. Gao, C.; Zhuang, J.; Zhou, C.; Ma, K.; Zhao, M.; Liu, C.; Liu, L.; Li, H.; Feng, F.; Sun, C. Prognostic value of aberrantly expressed methylation gene profiles in lung squamous cell carcinoma: A study based on The Cancer Genome Atlas. J. Cell. Physiol. 2019, 234, 6519-6528. [CrossRef]

19. Lee, J.Y.; Lee, W.K.; Park, J.Y.; Kim, D.S. Prognostic value of Iroquois homeobox 1 methylation in non-small cell lung cancers. Genes Genom. 2020, 42, 571-579. [CrossRef]

20. Jung, I.H.; Jung, D.E.; Chung, Y.Y.; Kim, K.S.; Park, S.W. Iroquois Homeobox 1 Acts as a True Tumor Suppressor in Multiple Organs by Regulating Cell Cycle Progression. Neoplasia 2019, 21, 1003-1014. [CrossRef]

21. Hsiung, C.A.; Lan, Q.; Hong, Y.C.; Chen, C.J.; Hosgood, H.D.; Chang, I.S.; Chatterjee, N.; Brennan, P.; Wu, C.; Zheng, W.; et al. The 5p15.33 locus is associated with risk of lung adenocarcinoma in never-smoking females in Asia. PLoS Genet. 2010, 6, e1001051. [CrossRef] [PubMed]

22. McKay, J.D.; Hung, R.J.; Gaborieau, V.; Boffetta, P.; Chabrier, A.; Byrnes, G.; Zaridze, D.; Mukeria, A.; Szeszenia-Dabrowska, N.; Lissowska, J.; et al. Lung cancer susceptibility locus at 5p15.33. Nat. Genet. 2008, 40, 1404-1406. [CrossRef] [PubMed]

23. Weissfeld, J.L.; Lin, Y.; Lin, H.M.; Kurland, B.F.; Wilson, D.O.; Fuhrman, C.R.; Pennathur, A.; Romkes, M.; Nukui, T.; Yuan, J.M.; et al. Lung Cancer Risk Prediction Using Common SNPs Located in GWAS-Identified Susceptibility Regions. J. Thorac. Oncol. 2015, 10, 1538-1545. [CrossRef] [PubMed]

24. Zanetti, K.A.; Wang, Z.; Aldrich, M.; Amos, C.I.; Blot, W.J.; Bowman, E.D.; Burdette, L.; Cai, Q.; Caporaso, N.; Chung, C.C.; et al. Genome-wide association study confirms lung cancer susceptibility loci on chromosomes 5 p15 and 15q25 in an African-American population. Lung Cancer 2016, 98, 33-42. [CrossRef]

25. Lonsdale, J.; Thomas, J.; Salvatore, M.; Phillips, R.; Lo, E.; Shad, S.; Hasz, R.; Walters, G.; Garcia, F.; Young, N.; et al. The Genotype-Tissue Expression (GTEx) project. Nat. Genet. 2013, 45, 580-585. [CrossRef] [PubMed]

26. Marchler-Bauer, A.; Bo, Y.; Han, L.; He, J.; Lanczycki, C.J.; Lu, S.; Chitsaz, F.; Derbyshire, M.K.; Geer, R.C.; Gonzales, N.R.; et al. CDD/SPARCLE: Functional classification of proteins via subfamily domain architectures. Nucleic Acids Res. 2017, 45, D200-D203. [CrossRef]

27. Wang, J.; Zhuang, J.; Iyer, S.; Lin, X.; Whitfield, T.W.; Greven, M.C.; Pierce, B.G.; Dong, X.; Kundaje, A.; Cheng, Y.; et al. Sequence features and chromatin structure around the genomic regions bound by 119 human transcription factors. Genome Res. 2012, 22, 1798-1812. [CrossRef]

28. Dammann, G.; Teschler, S.; Haag, T.; Altmuller, F.; Tuczek, F.; Dammann, R.H. Increased DNA methylation of neuropsychiatric genes occurs in borderline personality disorder. Epigenetics 2011, 6, 1454-1462. [CrossRef] 
29. Ghandi, M.; Huang, F.W.; Jané-Valbuena, J.; Kryukov, G.V.; Lo, C.C.; McDonald, E.R.; Barretina, J.; Gelfand, E.T.; Bielski, C.M.; Li, H.; et al. Next-generation characterization of the Cancer Cell Line Encyclopedia. Nature 2019, 569, 503-508. [CrossRef]

30. Molenaar, J.J.; Koster, J.; Zwijnenburg, D.A.; van Sluis, P.; Valentijn, L.J.; van der Ploeg, I.; Hamdi, M.; van Nes, J.; Westerman, B.A.; van Arkel, J.; et al. Sequencing of neuroblastoma identifies chromothripsis and defects in neuritogenesis genes. Nature 2012, 483, 589-593. [CrossRef]

31. Iorio, F.; Knijnenburg, T.A.; Vis, D.J.; Bignell, G.R.; Menden, M.P.; Schubert, M.; Aben, N.; Gonçalves, E.; Barthorpe, S.; Lightfoot, H.; et al. A Landscape of Pharmacogenomic Interactions in Cancer. Cell 2016, 166, 740-754. [CrossRef]

32. Diez-Villanueva, A.; Mallona, I.; Peinado, M.A. Wanderer, an interactive viewer to explore DNA methylation and gene expression data in human cancer. Epigenetics Chromatin 2015, 8, 22. [CrossRef]

33. Nagy, A.; Lanczky, A.; Menyhart, O.; Gyorffy, B. Validation of miRNA prognostic power in hepatocellular carcinoma using expression data of independent datasets. Sci. Rep. 2018, 8, 9227. [CrossRef]

34. Modhukur, V.; Iljasenko, T.; Metsalu, T.; Lokk, K.; Laisk-Podar, T.; Vilo, J. MethSurv: A web tool to perform multivariable survival analysis using DNA methylation data. Epigenomics 2018, 10, 277-288. [CrossRef]

35. Fiorentino, F.P.; Giordano, A. The tumor suppressor role of CTCF. J. Cell. Physiol. 2012, 227, 479-492. [CrossRef]

36. Witcher, M.; Emerson, B.M. Epigenetic silencing of the p16(INK4a) tumor suppressor is associated with loss of CTCF binding and a chromatin boundary. Mol. Cell 2009, 34, 271-284. [CrossRef]

37. De La Rosa-Velazquez, I.A.; Rincon-Arano, H.; Benitez-Bribiesca, L.; Recillas-Targa, F. Epigenetic regulation of the human retinoblastoma tumor suppressor gene promoter by CTCF. Cancer Res. 2007, 67, 2577-2585. [CrossRef]

38. Haag, T.; Richter, A.M.; Schneider, M.B.; Jimenez, A.P.; Dammann, R.H. The dual specificity phosphatase 2 gene is hypermethylated in human cancer and regulated by epigenetic mechanisms. BMC Cancer 2016, 16, 49. [CrossRef]

39. Haag, T.; Herkt, C.E.; Walesch, S.K.; Richter, A.M.; Dammann, R.H. The apoptosis associated tyrosine kinase gene is frequently hypermethylated in human cancer and is regulated by epigenetic mechanisms. Genes Cancer 2014, 5, 365-374. [CrossRef] [PubMed]

40. Victoria-Acosta, G.; Vazquez-Santillan, K.; Jimenez-Hernandez, L.; Munoz-Galindo, L.; Maldonado, V.; Martinez-Ruiz, G.U.; Melendez-Zajgla, J. Epigenetic silencing of the XAF1 gene is mediated by the loss of CTCF binding. Sci. Rep. 2015, 5, 14838. [CrossRef]

41. Wan, L.; Li, X.; Shen, H.; Bai, X. Quantitative analysis of EZH2 expression and its correlations with lung cancer patients' clinical pathological characteristics. Clin. Transl. Oncol. 2013, 15, 132-138. [CrossRef] [PubMed]

42. Wang, X.; Zhao, H.; Lv, L.; Bao, L.; Wang, X.; Han, S. Prognostic Significance of EZH2 Expression in Non-Small Cell Lung Cancer: A Meta-analysis. Sci. Rep. 2016, 6, 19239. [CrossRef] [PubMed]

43. Lu, T.P.; Tsai, M.H.; Lee, J.M.; Hsu, C.P.; Chen, P.C.; Lin, C.W.; Shih, J.Y.; Yang, P.C.; Hsiao, C.K.; Lai, L.C.; et al. Identification of a novel biomarker, SEMA5A, for non-small cell lung carcinoma in nonsmoking women. Cancer Epidemiol. Biomark. Prev. 2010, 19, 2590-2597. [CrossRef] [PubMed]

44. Meister, M.; Belousov, A.; Xu, E.C.; Schnabel, P.; Warth, A.; Hoffmann, H.; Dienemann, H.; Riedlinger, J.; Bodenmueller, H.; Zolg, W.; et al. Intra-tumor Heterogeneity of Gene Expression Profiles in Early Stage Non-Small Cell Lung Cancer. J. Bioinform. Res. Stud. 2014, 1, 1-20.

45. Huang, S.; Reitze, N.J.; Ewing, A.L.; McCreary, S.; Uihlein, A.H.; Brower, S.L.; Wang, D.; Wang, T.; Gabrin, M.J.; Keating, K.E.; et al. Analytical Performance of a 15-Gene Prognostic Assay for Early-Stage Non-Small-Cell Lung Carcinoma Using RNA-Stabilized Tissue. J. Mol. Diagn. 2015, 17, 438-445. [CrossRef] [PubMed]

46. Kuhn, A.; Loscher, D.; Marschalek, R. The IRX1/HOXA connection: Insights into a novel $t(4 ; 11)$ - specific cancer mechanism. Oncotarget 2016, 7, 35341-35352. [CrossRef] [PubMed]

47. Davis, S.; Meltzer, P.S. GEOquery: A bridge between the Gene Expression Omnibus (GEO) and BioConductor. Bioinformatics 2007, 23, 1846-1847. [CrossRef]

48. Lu, J.; Song, G.; Tang, Q.; Zou, C.; Han, F.; Zhao, Z.; Yong, B.; Yin, J.; Xu, H.; Xie, X.; et al. IRX1 hypomethylation promotes osteosarcoma metastasis via induction of CXCL14/NF-kappaB signaling. J. Clin. Investig. 2015, 125, 1839-1856. [CrossRef] 
49. Wang, T.; Xu, Y.; Hou, P. Identifying novel biomarkers of gastric cancer through integration analysis of single nucleotide polymorphisms and gene expression profile. Int. J. Biol. Markers 2015, 30, 321-326. [CrossRef]

50. Hark, A.T.; Schoenherr, C.J.; Katz, D.J.; Ingram, R.S.; Levorse, J.M.; Tilghman, S.M. CTCF mediates methylation-sensitive enhancer-blocking activity at the H19/Igf2 locus. Nature 2000, 405, 486-489. [CrossRef]

51. Yoon, B.; Herman, H.; Hu, B.; Park, Y.J.; Lindroth, A.; Bell, A.; West, A.G.; Chang, Y.; Stablewski, A.; Piel, J.C.; et al. Rasgrf1 imprinting is regulated by a CTCF-dependent methylation-sensitive enhancer blocker. Mol. Cell. Biol. 2005, 25, 11184-11190. [CrossRef] [PubMed]

52. Katainen, R.; Dave, K.; Pitkanen, E.; Palin, K.; Kivioja, T.; Valimaki, N.; Gylfe, A.E.; Ristolainen, H.; Hanninen, U.A.; Cajuso, T.; et al. CTCF/cohesin-binding sites are frequently mutated in cancer. Nat. Genet. 2015, 47, 818-821. [CrossRef] [PubMed]

53. Vire, E.; Brenner, C.; Deplus, R.; Blanchon, L.; Fraga, M.; Didelot, C.; Morey, L.; Van Eynde, A.; Bernard, D.; Vanderwinden, J.M.; et al. The Polycomb group protein EZH2 directly controls DNA methylation. Nature 2006, 439, 871-874. [CrossRef] [PubMed]

54. Strunnikova, M.; Schagdarsurengin, U.; Kehlen, A.; Garbe, J.C.; Stampfer, M.R.; Dammann, R. Chromatin inactivation precedes de novo DNA methylation during the progressive epigenetic silencing of the RASSF1A promoter. Mol. Cell. Biol. 2005, 25, 3923-3933. [CrossRef]

55. Huston, J.H.; Ryan, J.J. The emerging role of epigenetics in pulmonary arterial hypertension: An important avenue for clinical trials (2015 Grover Conference Series). Pulm. Circ. 2016, 6, 274-284. [CrossRef]

56. Rowbotham, S.P.; Kim, C.F. Diverse cells at the origin of lung adenocarcinoma. Proc. Natl. Acad. Sci. USA 2014, 111, 4745-4746. [CrossRef]

57. Bennett, K.L.; Romigh, T.; Eng, C. Disruption of Transforming Growth Factor- Signaling by Five Frequently Methylated Genes Leads to Head and Neck Squamous Cell Carcinoma Pathogenesis. Cancer Res. 2009, 69, 9301-9305. [CrossRef]

58. Dammann, R.; Strunnikova, M.; Schagdarsurengin, U.; Rastetter, M.; Papritz, M.; Hattenhorst, U.E.; Hofmann, H.S.; Silber, R.E.; Burdach, S.; Hansen, G. CpG island methylation and expression of tumourassociated genes in lung carcinoma. Eur. J. Cancer 2005, 41, 1223-1236. [CrossRef]

59. Muley, T.R.; Herth, F.J.; Schnabel, P.A.; Dienemann, H.; Meister, M. From tissue to molecular phenotyping: Pre-analytical requirements heidelberg experience. Transl. Lung Cancer Res. 2012, 1, 111-121. [CrossRef]

60. Helmbold, P.; Richter, A.M.; Walesch, S.; Skorokhod, A.; Marsch, W.; Enk, A.; Dammann, R.H. RASSF10 promoter hypermethylation is frequent in malignant melanoma of the skin but uncommon in nevus cell nevi. J. Investig. Dermatol. 2012, 132, 687-694. [CrossRef]

61. McShane, L.M.; Altman, D.G.; Sauerbrei, W.; Taube, S.E.; Gion, M.; Clark, G.M.; Statistics Subcommittee of the NCIEWGoCD. Reporting recommendations for tumor marker prognostic studies. J. Clin. Oncol. 2005, 23, 9067-9072. [CrossRef] [PubMed]

62. Schneider, M.A.; Granzow, M.; Warth, A.; Schnabel, P.A.; Thomas, M.; Herth, F.J.; Dienemann, H.; Muley, T.; Meister, M. Glycodelin: A New Biomarker with Immunomodulatory Functions in Non-Small Cell Lung Cancer. Clin. Cancer Res. 2015, 21, 3529-3540. [CrossRef] [PubMed]

63. Bustin, S.A.; Benes, V.; Garson, J.A.; Hellemans, J.; Huggett, J.; Kubista, M.; Mueller, R.; Nolan, T.; Pfaffl, M.W.; Shipley, G.L.; et al. The MIQE guidelines: Minimum information for publication of quantitative real-time PCR experiments. Clin. Chem. 2009, 55, 611-622. [CrossRef] [PubMed]

64. Deutschmeyer, V.; Breuer, J.; Walesch, S.K.; Sokol, A.M.; Graumann, J.; Bartkuhn, M.; Boettger, T.; Rossbach, O.; Richter, A.M. Epigenetic therapy of novel tumour suppressor ZAR1 and its cancer biomarker function. Clin. Epigenetics 2019, 11, 182. [CrossRef] [PubMed]

Publisher's Note: MDPI stays neutral with regard to jurisdictional claims in published maps and institutional affiliations.

(C) 2020 by the authors. Licensee MDPI, Basel, Switzerland. This article is an open access article distributed under the terms and conditions of the Creative Commons Attribution (CC BY) license (http://creativecommons.org/licenses/by/4.0/). 